\title{
Pricing decisions in peer-to-peer and prosumer-centred electricity markets: Experimental analysis in Germany and the United Kingdom
}

\author{
Ulf J.J. Hahnel ${ }^{1 *}$ and Michael J. Fell ${ }^{2}$ \\ ${ }^{1}$ Department of Psychology and Swiss Center for Affective Sciences, University of Geneva, Switzerland. \\ ${ }^{2}$ UCL Energy Institute, University College London, UK \\ *ulf.hahnel@unige.ch; Word Count: 7983
}

\begin{abstract}
Prosumer-centred electricity market models such as peer-to-peer communities can enable optimized supply and demand of locally generated electricity as well as an active participation of citizens in the energy transition. An important element of active participation is the improved ability of community members to identify and choose who they transact with in a much more granular way than is usual. Despite this key novelty and the social core of prosumer-centred markets, little is known about how citizens would trade with different actors involved in the system. Here, we report a preregistered cross-national experiment in which we investigated individual trading preferences in a peer-to-peer community, including a variety of private and non-private trading actors. Our data from the United Kingdom ( $n=441)$ and Germany $(n=440)$ shows that set buying and selling prices strongly vary, pointing to three systematically different trading strategies that individuals apply as a function of involved trading actor. Findings moreover reveal that trading decisions are determined by individuals' political orientation, place attachment, and climate change beliefs as well as individual differences in trust in the involved trading actor. Finally, our results illustrate high consistency in trading preferences across nations. However, nation-level differences emerged when decisions were made publicly visible, emphasising the need to consider context-effects in peer-to-peer system design. Our results have implications for the development of prosumer-centred energy models and the design of interventions to increase citizen participation across national contexts.
\end{abstract}

Keywords: Peer-to-Peer Trading; Energy Communities; Price Setting; Cross-National Research; Trading Decisions; Peer-to-Peer Actor; Trust; Place Attachment; Political Orientation

\section{Highlights}

- Preregistered study on actor-specific price settings in P2P energy communities

- Set buying and selling prices strongly depend on involved trading actor

- Identification of three trading patterns that are applied depending on trading actor

- The impact of private vs. public price settings depends on national context

- Political orientation, place attachment, beliefs, and trust influence decisions

\section{List of abbreviations}

- DER: Distributed energy resource

- P2P: Peer-to-Peer

- PCM: Prosumer-Centred Model

- UK: United Kingdom 


\subsection{Introduction}

Recent years have seen the emergence of prosumer-centred electricity market models such as peer-to-peer (P2P) trading and local energy markets [1-5]. These involve prosumers and consumers making electricity transactions directly between each other, or within relatively small local groupings. Such models are characterised by improved ability of system users to identify and choose who they transact with in a much more granular way than is usual. It is this characteristic, and its possible implications, that motivate the research we present here.

Today's centralised retail electricity markets mostly involve small users purchasing electricity indirectly from a small number of large, asset-owning generators through a single supplier. In a Prosumer-Centred Model (PCM), depending on the design of the scheme, participants may be able to transact not just with, for example, users they know to be local, but potentially specific individuals or groups. For example, services could attract customers with the option of trading at reduced rates with friends and family, or supporting a local school by purchasing power at a price premium from them [6].

A substantial amount of research effort in recent years has been directed at understanding how PCMs can be designed to support network management [3] while also delivering user benefits such as reduced bills [7]. Increasingly, attention is also being paid to the role of participant decision-making in such trading $[8,9]$. However, limited previous research has examined how people's trading preferences vary depending on the $\mathrm{P} 2 \mathrm{P}$ trading actor involved in the transaction (for exceptions see: [6]).

The aim of the research we present here was therefore to investigate whether people set different trading preferences for different actor groups participating in a P2P-based PCM, and to explore psychological factors underlying their decision preferences. We also aimed to test whether changes in the choice setting, that is whether or not participants were informed that their decisions are publicly visible would influence trading decisions. We used nationally representative experiments in Germany and the United Kingdom (UK) to answer the following preregistered research questions:

1. Do people set different energy trading price preferences with different PCM actors and, if so, why? 
2. Is there a difference in set trading price preferences depending on whether preferences are publicly visible or not?

3. Are there country-level differences in set trading price preferences?

4. How do set trading price preferences vary with respondent characteristics (demographic, psychological traits, psychological trading-specific variables, respondent-actor relations)?

The next section reviews previous research relevant to these questions. We then detail our method and findings, before discussing their implications for policy and practice. In reporting the study we broadly follow the CONSORT guidelines for reporting of randomised control trials [10].

\subsection{Willingness to share energy in prosumer-centred models}

The electricity we use has mostly obscure origins. It may have been generated by a nuclear reactor, by burning methane, or by a wind turbine - and the generator could have been situated locally or in another country. Whatever the source, it appears as an homogeneous commodity. In recent decades, customers have had the choice of purchasing power from renewable generators. In early 2021 these accounted for over half of tariffs on offer in the UK [11]. While there are questions around the origin claims made for renewable tariffs [12], there is clear demand for products that permit choice of energy source and the expression of nonfinancial motivations.

Advances in metering and information and communication technology (ICT) now offer the prospect of much finer grained tracking of the origin and destination of electricity - at least for accounting purposes. This, in combination with rises in the penetration of distributed energy resources (DERs), has led to the emergence of PCMs such as P2P electricity trading. While real examples of such schemes are still mainly limited to small field trials, they are the subject of substantial interest in research, policy, and practice. Consumer research suggests they are popular in principle, with studies consistently finding stated interest in participating in the order of $50-80 \%[9,13-15]$.

While P2P electricity trading does not necessarily have to take place within a locality, this is the most common use case. Mixed evidence is emerging as to the value placed on local electricity. In a German choice experiment Mengelkamp et al. [16] found that both greenness 
and localness in electricity were somewhat valued. The results differed for an all-Germany and a regional sample (Allgäu), and except for a slight willingness to pay more for regional electricity in the regional sample, there was no indication that localness was viewed as a premium characteristic for which participants would actually pay more. Wörner et al. [17] worked with 31 participants in a real P2P trading scheme, exploring actual setting of buy and sell prices. In a pre-survey, around half the participants suggested they would be prepared to pay a premium for renewable or local generation. However, with some temporary exceptions, real-world price settings generally indicated a lack of inclination either to pay premium prices for renewable/local energy, or sell at a discount that would take the price below that received through the feed-in tariff. The limited evidence available so far therefore suggests that little if any premium is placed on local over non-local electricity.

When more information about the identity of local trading actors is introduced in research, a nuanced picture emerges. In interviews conducted by Pumphrey et al. [18], some participants expressed concern about doing financial business with neighbours, because of the personal conflict that could result. A survey experiment by Fell et al. [15] also found that people were more likely to participate in trading schemes that operate at a city/region rather than hyperlocal level. However, for some the idea of trading with neighbours is an attraction to participate, as found by Scuri et al. [19], in a study of 10 households on the Portuguese island of Madeira. Even there, however, some preference was expressed for donation rather than payment, out of respect for the neighbourly relationship. This dynamic was further highlighted in an ethnographic study reported by Singh et al. [20], who studied sharing of access to solar generation for uses such as mobile phone charging in rural India. Participants' preference for financial or other (more social) forms of exchange differed depending on the relationship between them, with financial returns preferred for more distant connections, and more social in-kind or intangible returns preferred for closer relationships.

There is some support in existing research for a preference to trade with specific households. A study by Wilkinson et al. [21] used focus group discussions with participants in an actual P2P trading scheme in Australia to explore their perceptions and motivations. A key desired feature highlighted by the participants and lacking from the design was the ability to trade with or support selectively other participants. Again, concern was expressed about the unequal ability to benefit, and there was a general dislike for the strongly market-driven (rather than community centred) nature of the scheme. 
Regarding more general motivations, an interview study by Wilkins et al. [22] highlights that the ability to trade with others in a locality is viewed by some as a way of building community cohesion, taking power back from large corporations, and promoting engagement in sustainability. However, there is again evidence of concern around the introduction of financial elements to relationships that lacked them previously, resulting in certain participants gaining power over others through having the ability to set (rather than take) prices. There were mixed views on the role of such schemes in addressing social challenges. While some participants saw potential in the ability to provide power prices to participants in fuel poverty, others were concerned by the dependency this would introduce on the altruism of others rather than more traditional centrally coordinated alleviation mechanisms. This discomfort with the idea of delegating too much socio-economic work to P2P communities is also present in a workshop study by Smale and Kloppenburg [23]. There was little appetite for using the communities as a redistributive mechanism, with a preference for using them to deliver some shared community objectives, such as facilities. However, research using a discrete choice experimental approach on a small $(N=72)$ sample of prosumers in the Netherlands found a high $(50 \%+)$ degree of willingness to donate excess electricity to low income households and community facilities [6].

Ecker et al. [8] experimentally investigated whether the price at which German participants would be happy to buy or sell electricity with neighbours differed depending on benefits framing. They found that participants set significantly lower buying prices and higher selling prices when autarky (independence of electricity supply) benefits were emphasised compared to a neutral condition. Hahnel et al. [9] built on this work to explore the more dynamic impact that current electricity price and the state of charge of a home battery have on trading decisions. Three main trading clusters emerged, with some participants' trading decisions being driven mainly by price, others being mainly driven by state of battery and some only trading when the state of charge exceeded a certain threshold.

The research we have reviewed suggests an interest in principle in engaging in P2P trading, with some appreciation of local electricity but limited willingness to pay more for it, and mixed willingness to trade electricity with friends and neighbours. To extend this work, we are interested in unpicking further the influence of the identities of local actors on people's trading preferences. This includes both domestic actors, such as neighbours and friends, but 
also non-domestic ones such as companies and public organisations like schools and hospitals. These organisations have the potential to become key players in local energy trading schemes due to their access to the space and economies of scale to install larger energy assets [24]. As set out in the next section, we explore this through an experimental online study, which requests participants to set default trading prices with a range of actors in a P2P scheme. This represents a halfway-house between active trading and no involvement in price-setting, both of which have been shown to be popular options in a real-world $\mathrm{P} 2 \mathrm{P}$ trial [25]. In contrast to most previous research, we assessed both selling and buying conditions (for exceptions see [8]). This design allowed us to not only investigate differences in volatility in set selling and buying prices but also to investigate trading decision-making strategies in more detail, including reciprocal, altruistic, and non-cooperative decision patterns as a function of the trading actor at hand.

\subsection{Determinants of trading decisions in prosumer-centred models}

The key novelty of PCM is the incorporation of the social dimension into energy supply and consumption. Handing over decision power to private actors requires cooperation among community members in order to ensure a functioning decentralised market. Fundamental theories on direct reciprocity suggest that human cooperation is built on an equilibrium of cooperation and defection among individuals [26,27]. Direct reciprocity implies the implicit assumption that cooperation will ultimately lead to cooperation, whereas defection will ultimately lead to defection. Research using economic games has accumulated evidence for associated tit-for-that mechanisms in human cooperation and illustrated that humans are willing to spend their own resources in order to punish group members that deviate from this principle [28,29]. First research has indicated that such basic principles underlying human cooperation also apply to the context of P2P energy trading: Homeowners set statistically identical buying and selling prices for self-generated electricity; a strategy associated with a tit-for-that principle. However, when their own independence was made salient by means of an experimental manipulation, homeowners shifted from this cooperative strategy to a noncooperative trading strategy in that they set higher selling prices relative to buying prices [8].

Trust is an essential component in highly cooperative environments such as PCM. Definitions of trust vary, but in the context of this research trust may be usefully understood as "the willingness of a party to be vulnerable to the actions of another party based on the expectation 
that the other will perform a particular action important to the trustor, irrespective of the ability to monitor or control that other party" [30] (p. 712). Trust is relevant because while participants in $\mathrm{P} 2 \mathrm{P}$ trading may set the terms on which they would be ready to trade with others, they are dependent on others' terms for trades to actually take place. For example, Community Member A may offer discounted energy to Member B and expect to get a discount in return - but while Member B would definitely realise a saving in this case, Member A's saving is dependent on Member B also choosing to offer a discount. In setting her default terms, Member A must trust Member B in display reciprocity [27]. While trust in energy suppliers has previously been shown to be associated with preference for participation in a range of electricity demand response offerings [31,32], its role has not yet been systematically explored in the context of P2P trading decisions. In light of the various actors involved in PCMs such as P2P energy schemes, it is key to understand how trust impacts trading decisions of community members as a function of the trading actor at hand.

Whereas direct reciprocity has been proven to be a powerful mechanism in human cooperation, it is ultimately limited in its ability to explain mere altruistic acts. The principle of indirect reciprocity provides a theoretical account for altruistic decisions in social groups. The main assumption is that altruistic acts, without direct rewards, may nevertheless pay out by increasing the reputation of the giver, which in turn will be rewarded by others. In accordance, there is evidence that making people's decisions public results in more prosocial behaviour, such as more generous charitable giving [33,34]. Price can be an important form of social signal, in which the identity of the signaler and receiver are both key considerations [35]. Knowledge of identity is thus an enabler of indirect reciprocity (based on acting to uphold reputation) [36], and is an essential consideration in approaches which view trading through a lens of behavioural game theory, which is concerned with departures from standard ideas of economic rationality [37]. To test the role of trading choice visibility, we introduced a between-subjects experimental factor to our study where one group was informed that their trading choices in the PCM would be visible on the platform, while another group was told their choices would remain confidential. Informed by evidence of prosocial behaviour when decisions are shown in public and the principle of indirect reciprocity, we hypothesised that in the publicly visible condition, participants will set higher buying prices and lower selling prices compared to the private condition. 
Cooperation behaviour is context dependent [38-40]. For instance, research administering behavioural experiments across 15 populations has shown that community size and market characteristics predict fairness and costly punishment in cooperation tasks [38]. In another study across 16 international populations, norms of civic cooperation and the rule of law predicted behaviour in public goods experiments [40]. Here, we accounted for national context by conducting the experimental study in two countries - Germany and the UK simultaneously. In addition to exploring the role of national context, this approach allowed us to improve the international generalisability of the findings. With some exceptions (e.g. [16]), most previous research has focused on a single country or locality, limiting the extent to which the role of context factors and cultural differences can be explored. The relevance of the local context is further reflected in the concept of place attachment. Place attachment has been linked to positive affective bonds to local groups and communities and a stronger identification with local actors [41]. Given the local nature of the PCM analysed here, we assumed that stronger individual place attachment is associated with stronger cooperation behaviour.

In addition to differences in place attachment, research has revealed further interindividual differences that directly or indirectly shape cooperation and altruism. Political orientation has been linked to differences in the perception of social inequality, the relevance of fairness, and variation in market and system justification beliefs $[42,43]$. We assumed that associated fundamental differences in belief systems underlying political orientations account for significant variance in trading decisions. We moreover tested the assumption that the impact of political orientation on decision outcomes largely depends on the involved trading actor. Cooperation with multinational companies, for instance, should depend on the extent to which the decision maker considers the actor to be a crucial element of the economic and social system; a belief that is formed by market and system justification beliefs [42]. Finally, given the relevance of PCM as an instrument to reduce carbon emissions [44,45], we tested whether differences in climate change beliefs explain variance in trading decisions. This approach is further in line with the fundamental assumption that environmental and altruistic concerns and values are largely interconnected [46,47].

Taken together, basic research on human cooperation has shown that direct and indirect reciprocity are fundamental principles underlying human cooperation behaviour. We infer three decision patterns from the literature and assume individuals to apply these patterns in 
the context of PCM: tit-for-tat, noncooperative, and altruistic decision patterns. In the present preregistered research, we investigated whether individuals apply different trading decision patterns in PCM as a function of the trading actor at hand and examined under which conditions trust modulates this decision-making process. We moreover examined the role of public visibility on trading decisions, grounded in the finding that reputation is a basic principle of cooperation. We finally accounted for the finding that context shapes cooperation decisions as well as for the impact of interindividual differences such as place attachment and climate change beliefs on decision-making.

\subsection{Material and methods}

The preregistration report, study data and code as well as the full study material are publicly available on the Open Science Framework: [To be shared upon journal publication]

\subsection{Sample}

In total 881 participants from the UK $(n=441)$ and Germany $(n=440)$ took part in the online study from December 7-13, 2020. Aiming for representative samples of the UK and German population, data was collected by a professional market research institute with participant panels in both countries. We applied quotas on age and gender. Participants received financial compensation for taking part in the study that took around 15 minutes. Only participants over 18 years were eligible to take part in the study. Descriptive statistics for the UK and German subsamples are depicted in Table 1. The study was approved by the ethics committee of the Faculty of Psychology and Educational Sciences of the University of Geneva, Switzerland. All participants gave their consent to take part in the study.

As research on $\mathrm{P} 2 \mathrm{P}$ energy trading preferences is still scarce, sample size was not determined on the basis of being able to detect a pre-specified effect size. Rather, it was determined by the resources available. Sample size has been predefined and reported in the preregistration report.

\subsection{Demographics and psychological measurements}

The procedure of the present study is illustrated in Figure 1. At the beginning of the study, participants answered a series of demographic questions including age, gender, political orientation, education, and employment status (cf., Table 1). After the trading task, we further 
assessed participants' climate change beliefs and place attachment using adapted versions of validated scales [48-50]. Climate change beliefs ("e.g., "Climate change is likely to have a big impact on people like me.") and place attachment (e.g., "My local area means a lot to me ") were measured with seven items each on a scale ranging from 1 - strongly disagree to 7 strongly agree. We assessed participants' trust towards the key actors involved in the P2P trading tasks (i.e., schools and hospitals, small businesses, large multinational companies, low-income households, groups of friends and family, and direct neighbours). Trust was measured using the item "How trustworthy do you consider each of the following groups?" and was answered for each actor individually on a scale ranging from 1 - very small extent to 5 - very large extent. Also, participants reported their current energy mix and PV system possession. The original version was developed in English and translated by native speakers to German for data collection in Germany.

Enter study: Informed consent

(Germany $n=440$, UK $n=441$ )

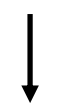

Pre-Survey: Demographics, political orientation

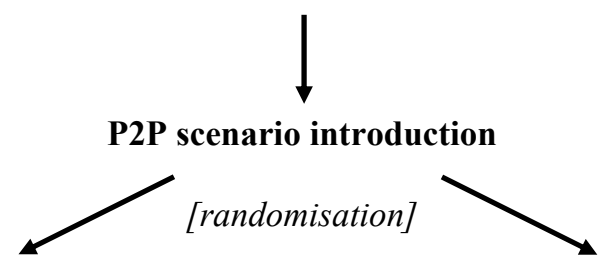

Informed trading choices are private

(Germany $n=218$, UK $n=226$ )

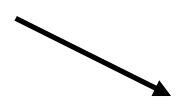

Trading task

(default buy/sell price setting for different actors)

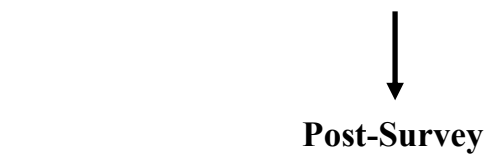

P2P evaluation and preferences, climate change beliefs, place attachment, trust in actors, COVID-19 context $^{1}$

\section{Exit study}

Figure 1. Design of the present study, including between-subjects experimental variation. Data was collected in the UK and Germany $\left(N_{\text {total }}=881\right)$. ${ }^{1}$ For a complete list of assessed variables see: [to be shared upon journal publication] 
Table 1. Characterization of the UK and German samples. Values reflect frequencies and mean values with standard deviations in parentheses. Statistically significant differences between the German and UK sample are marked in bold.

\begin{tabular}{|c|c|c|}
\hline & $\begin{array}{l}\text { Germany } \\
(N=440)\end{array}$ & $\begin{array}{c}\mathrm{UK} \\
(N=441)\end{array}$ \\
\hline \multicolumn{3}{|l|}{ Sex } \\
\hline Female & $50.2 \%$ & $50.1 \%$ \\
\hline Age & $46.72(16.9)$ & $45.97(16.5)$ \\
\hline \multicolumn{3}{|l|}{ Employment status } \\
\hline Student & $9.3 \%$ & $6.1 \%$ \\
\hline Unemployed & $3.9 \% * * *$ & $10.7 \% * * *$ \\
\hline Full-time & $43.6 \%$ & $48.5 \%$ \\
\hline Part-time & $11.4 \%$ & $14.5 \%$ \\
\hline Retiree & $21.4 \%$ & $16.3 \%$ \\
\hline Other & $10.5 \% * * *$ & $3.9 \% * * *$ \\
\hline \multicolumn{3}{|l|}{ Education } \\
\hline Primary school & $8.9 \% * * *$ & $0.2 \% * * *$ \\
\hline Secondary school & $30.9 \% * *$ & $21.8 \% * *$ \\
\hline Further education & $25.5 \%$ & $23.8 \%$ \\
\hline $\begin{array}{l}\text { Higher education/ } \\
\text { Undergraduate }\end{array}$ & $13.4 \% * * *$ & $35.4 \% * * *$ \\
\hline $\begin{array}{l}\text { Higher education/ } \\
\text { Postgraduate }\end{array}$ & $18.6 \%$ & $18.1 \%$ \\
\hline Other qualification & $2.7 \% *$ & $0.7 \% *$ \\
\hline Household members & $2.21(1.12)^{* * *}$ & $2.59(1.36)^{* * *}$ \\
\hline \multicolumn{3}{|l|}{ Energy mix } \\
\hline $100 \%$ renewable & $30.0 \%$ & $31.7 \%$ \\
\hline Fossil/renewable mix & $41.6 \% * * *$ & $29.3 \% * * *$ \\
\hline Do not know & $28.4 \% * *$ & $39.0 \% * *$ \\
\hline PV possession & $9.1 \%$ & $8.4 \%$ \\
\hline \multicolumn{3}{|l|}{ Purchase intention ${ }^{1}$} \\
\hline$P V$ & $2.62(2.02)^{* * *}$ & $3.15(2.08) * * *$ \\
\hline$E S S$ & $2.61(2.03)$ & $2.80(1.89)$ \\
\hline Political orientation ${ }^{2}$ & $4.97(1.63)^{*}$ & $5.23(1.86)^{*}$ \\
\hline
\end{tabular}




\begin{tabular}{|c|c|c|}
\hline $\begin{array}{l}\text { Climate change } \\
\text { acceptance }^{3}\end{array}$ & $5.14(1.18)^{* *}$ & $4.88(1.09)^{* * *}$ \\
\hline Place attachment ${ }^{4}$ & $4.91(1.17)$ & $4.82(1.27)$ \\
\hline \multicolumn{3}{|l|}{ COVID-19 } \\
\hline Daily routines $^{5}$ & 3.3 (1.19) & $3.41(1.22)$ \\
\hline Financial situation $^{6}$ & $2.85(0.76)$ & $2.82(0.93)$ \\
\hline \multicolumn{3}{|c|}{$\begin{array}{l}\text { Note. } \mathrm{PV}=\text { photovoltaic system, ESS }=\text { energy storage system; }{ }^{1} \text { technology purchase } \\
\text { intention (within next } 5 \text { years) ranged from } 1-\text { very unlikely to } 7-\text { very likely; }{ }^{2} \text { political } \\
\text { orientation ranged from } 1-\text { extremely left to } 10-\text { extremely right; }{ }^{3} \text { Climate change } \\
\text { beliefs ("Climate change is likely to have a big impact on people like me.") varied from } 1 \\
- \text { strongly disagree to } 7-\text { strongly agree; }{ }^{4} \text { Place attachment (e.g. "My local area means a } \\
\text { lot to me") ranged from } 1-\text { strongly disagree to } 7-\text { strongly agree; }{ }^{5} \mathrm{COVID}-19 \text { change } \\
\text { daily routines ranged from } 1-\text { very small extent to } 5-\text { very large extent; }{ }^{6} \mathrm{COVID}-19 \\
\text { change in financial situation ranged from } 1-\text { lot worse to } 5-\text { lot better; } * * * p<.001 ; * * \\
p<.01 ; * p<.05\end{array}$} \\
\hline
\end{tabular}

\subsection{P2P scenario introduction}

After providing demographic information, participants were forwarded to the $\mathrm{P} 2 \mathrm{P}$ trading scenario. Given that most individuals had no experience with P2P communities at the point of data collection, this section was designed to provide participants with a realistic image of a possible $\mathrm{P} 2 \mathrm{P}$ community in a clear and understandable manner. Participants were asked to imagine that they have just moved within their local area into a new home with solar panels on the roof, allowing them to generate their own electricity with their own PV system. It was further described that participants were already part of an energy network scheme called PowerClub, run by their local authority, which let members trade (i.e. buy and sell) electricity they produce, but do not need themselves, directly between each other. Members were people and organisations in the local area who wanted to sell their renewable energy or buy renewable energy from local actors. The purpose of the scheme was to support uptake of lowcarbon power sources, and help manage the local electricity network.

Participants were further informed about the group of people and organisations taking part in the network: direct neighbours (i.e., the ten nearest households), a selected group of local friends and family members, local low-income households (e.g., people living in social housing), schools and hospitals, small businesses (e.g., local shops), and large multinational companies that have offices in the local area. As members of the scheme PowerClub participants had the opportunity to set their trading preferences with different groups of 
people and organisations. Specifically, they could choose the price at which they wanted to trade electricity with each group (i.e., set buying and selling price for each actor). We experimentally randomised between subjects whether participants were informed that their selling and buying preferences were made publicly available on their profile $(n=437)$ or were only visible in their private profile $(n=444)$ and thus whether or not their decisions were visible by the other members of the scheme.

\subsection{P2P trading tasks}

After the introduction section, participants set their preferred buying and selling prices for each group of community members. The order of trading tasks (buying and selling) was randomised. See SM Note 1 for additional information on the task.

In the buying condition, participants were asked to set the unit price (i.e., $1 \mathrm{kWh}$ ) at which they would be willing to buy surplus electricity from the groups taking part in the PowerClub scheme (i.e. the price they would be willing to pay). Participants could choose to (i) buy electricity from the groups at the default electricity price of the scheme (i.e., 15 pence $/ \mathrm{kWh}$ and $30 € C$ ent/kWh in the UK and Germany, respectively), (ii) offer groups a premium, or (iii) ask them for a discount using a scale ranging from -5 pence $/ \mathrm{kWh}[€ \mathrm{Cent} / \mathrm{kWh}]$ to +5 pence/kWh [€Cent $/ \mathrm{kWh}$ ) with default unit price as midpoint. That is, positive values reflected that participants offered price premium and negative values reflected that participants asked for a discount.

In the selling condition, participants were asked to set the unit price at which they would be willing to sell their surplus electricity to the groups taking part in the PowerClub scheme (i.e. the price the groups would pay). Participants could choose to (i) sell electricity to the groups at the default electricity price of the scheme (i.e., 15 pence/kWh and $30 € C e n t / k W h$ in the UK and Germany, respectively), (ii) ask groups to pay a premium, or (iii) offer them a discount using a scale ranging from -5 pence $/ \mathrm{kWh}[€ \mathrm{Cent} / \mathrm{kWh}$ ) to +5 pence $/ \mathrm{kWh}[€ C$ ent $/ \mathrm{kWh}]$ with default unit price as midpoint. That is, positive values reflected that participants asked for a price premium and negative values reflected that participants offered a discount.

\subsection{P2P evaluation and implementation}

After conducting the $\mathrm{P} 2 \mathrm{P}$ trading task, participants answered whether they would prefer to be able to set prices or would prefer prices to be set automatically. Those participants who 
indicated that they would prefer to set prices (i.e., 63.6\%), were additionally asked whether they would prefer to set prices for each actor individually or to set one price that applies to all actors. $84.1 \%$ preferred the option to set different selling and buying prices for each group of actors taking part in the electricity community over the option that the same selling and buying prices are applied across all actors. Moreover, participants reported how attractive they find an electricity community on a scale from 1 - not attractive at all to 7 -very attractive. On average, participation in an electricity community similar to the one presented in the present research was rated as rather attractive $(M=4.85, S D=1.74)$.

\subsection{Data analysis}

We examined our main research questions as defined in the preregistration report. In order to answer Research Question 1 on variation in $\mathrm{P} 2 \mathrm{P}$ energy trading preferences as a function of actor group, we computed a linear model with the two within-subjects factors trading condition (buying/selling) and trading actor (i.e., schools and hospitals/small businesses/multinational companies/low-income households/friends and family/direct neighbours) and set trading prices as dependent variable. Trading price was assessed as the difference from the default energy price and could range from -5 to +5 pence $/ \mathrm{kWh}$ [€Cent/kWh]. We moreover controlled for nation (UK/Germany) and visibility of trading decisions (public/private) as well as for random effects on the subject level. To examine Research Questions 2 and 3 we analysed buying and selling decisions separately and added the interaction terms of the between-subjects factors visibility (public/private) and nation (UK/Germany) to the model. We tested the preregistered hypothesis that "In the publicly visible condition, participants will set higher buy prices and lower sell prices compared to in the private condition".

To examine Research Question 4, we again examined buying and selling decisions separately and added political orientation, climate change beliefs, place attachment as well as their interaction terms with trading actor to the model. We finally examined effects of trust towards the actors on set trading prices while controlling for political orientation, climate change beliefs, and place attachment. The independent variables were $\mathrm{z}$-standardised prior to the analyses. 


\subsection{Results}

\subsection{Differences in energy trading price preferences depending on P2P actor (Research}

\section{Question 1)}

As illustrated in Figure 2, the variation in decisions was greater in the selling condition compared to the buying condition. Overall, however, there was no statistically significant difference between set selling and buying prices $(F(1,9691)=1.55, p=.212)$.

Importantly, participants set different trading prices depending on the involved actor $(F(1$, 9691) $=178.29, p<.001$ ). As illustrated in Figure 2, prices set for different actors were subject to the trading condition $(F(1,9691)=368.05, p<.001)$, pointing to three different trading patterns: participants either set similar prices in the selling and buying condition (tit-for-tat pricing), offered discounts in the selling condition, but did not request similar discounts in the buying condition (altruistic pricing), or requested discounts in the buying condition but asked for price premium in the selling condition (noncooperative pricing). A tit-for-tat trading pattern was more likely when participants traded with neighbours $\left(\chi^{2}(1)=1.08, p=.299\right)$ and small businesses $\left(\chi^{2}(1)=4.837, p=.056\right)$. An altruistic trading pattern was more likely when they traded with friends and family $\left(\chi^{2}(1)=112.58, p<.001\right)$, schools and hospitals $\left(\chi^{2}(1)=59.56, p<.001\right)$, and low-income households $(\chi 2(1)=285.67, p<.001)$. A noncooperative trading patterns was more likely when they traded with large multinational companies $\left(\chi^{2}(1)=59.56, p<.001\right)$. See Supplementary Tables 1-2 for complete results. 


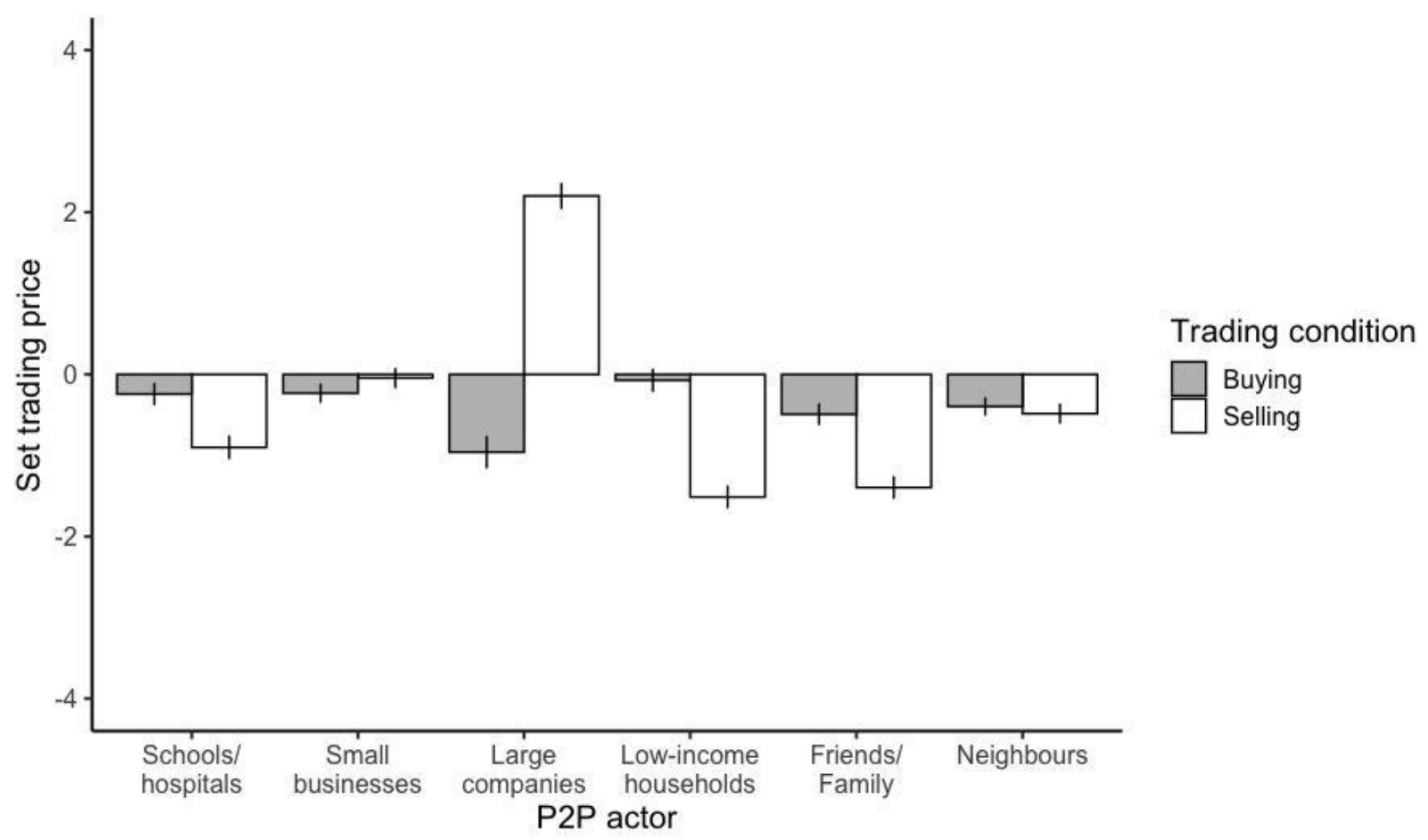

Figure 2. Set trading prices as a function of trading actor and trading condition (selling/buying). Values on the $y$-axis refer to differences in $€ /$ Cent (German sample) and pence (UK sample) from the default electricity price. That is, in the selling condition, positive values reflect that participants asked for a price premium and negative values reflect that participants offered a discount. In the buying condition, positive values reflect that participants offered a price premium and negative values reflect that participants asked for a discount. Error bars depict 95\% confidence intervals.

\subsection{Differences in energy trading price preferences depending on visibility and nation}

\section{(Research Questions 2-3)}

On average across the UK and Germany there was no significant difference in buying or selling price preferences between the visible and non-visible conditions, meaning that our preregistered hypothesis was not supported. However, we did observe differences in the effect of visibility between the UK and Germany.

UK participants set overall higher prices compared to German participants in the selling condition $(F(1,881)=12.53, p<.001)$. As illustrated in Figure 3a, this effect was subject to the visibility of trading choices $(F(1,881)=3.93, p=.048)$ in that set selling prices did not differ between nations when they were made privately $(\chi 2(1)=1.223, p=.269)$ but significantly differed between nations when they were made in public $(\chi 2(1)=15.12, p<.001)$. Specifically, UK participants offered smaller price discounts than German participants when their trading 
decisions were publicly visible. This effect was independent of the trading actor $(F(1$, $4405)=1.97, p=080$ ). See Supplementary Tables 3-4 for complete results.

A similar pattern was observed in the buying condition in which national differences were likewise subject to the visibility of trading decisions $(F(1,881)=5.61, p=.018)$. As illustrated in Figure 3b, set buying prices did not differ between nations when they were made privately $(\chi 2(1)=0.27, p=.600)$ but significantly differed between nations when they were made in public $(\chi 2(1)=7.93, p=.010)$. Specifically, UK participants asked for smaller price discounts than German participants when their trading decisions were publicly visible. This effect was independent of the trading actor $(F(1,4405)=0.352, p=.881)$. See Supplementary Tables 5-6 for complete model results. In addition, it was indicated that UK and German participants differ in the extent to which they set buying prices depending on trading actor $(F(1,4405)=3.242, p=.006)$. Post-doc tests however did not reveal national differences for any of the six actors $(\chi 2(1) \leq 6.30, p \geq .072)$. See Supplementary Table 7 for complete model results.
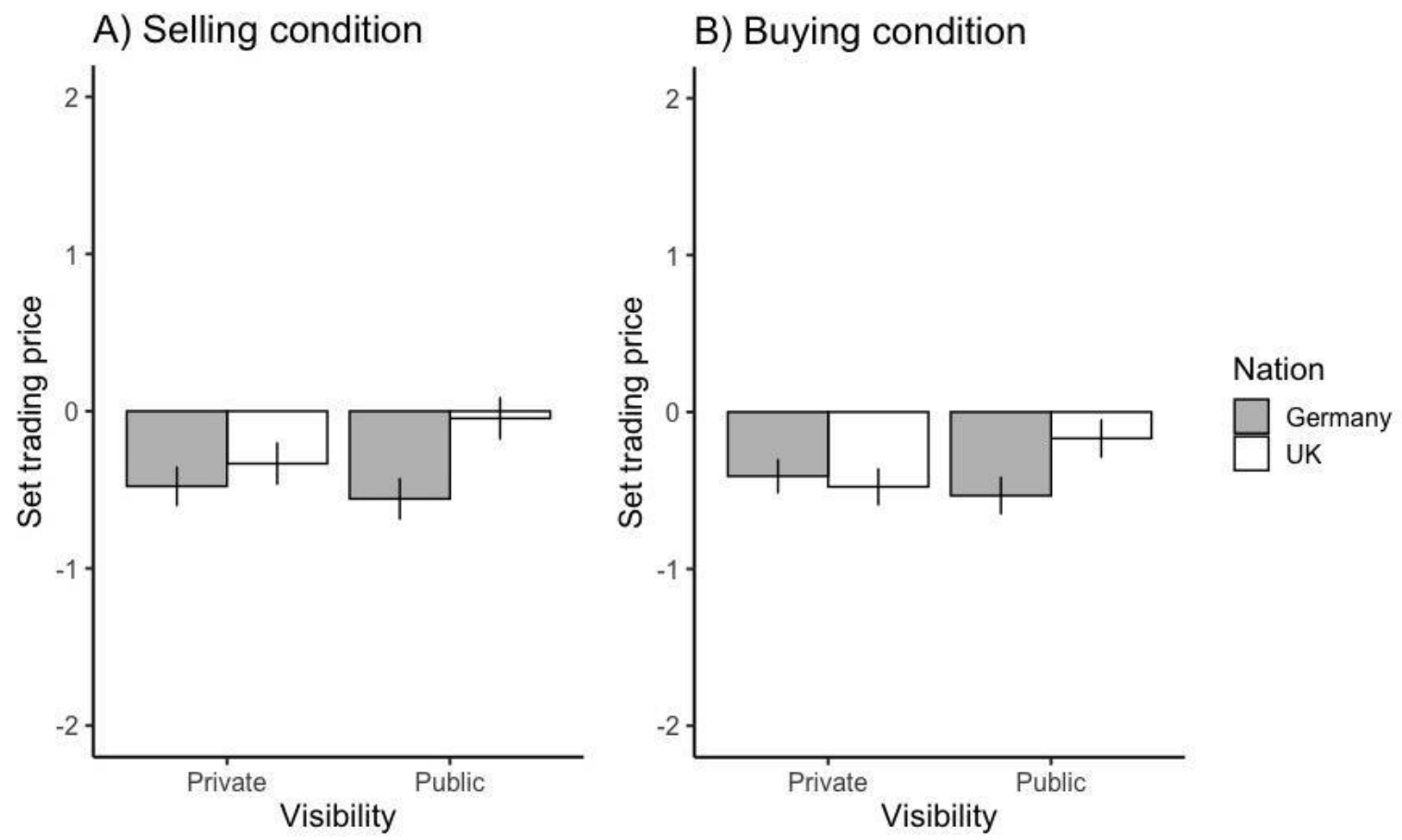

Figure 3. Set selling prices A) and buying prices B) as a function of nation and visibility of trading decisions (private/public). Values on the y-axis refer to differences in $€ /$ Cent (German sample) and pence (UK sample) from the default electricity price. Error bars depict $95 \%$ confidence intervals. 


\subsection{Influence of psychological variables on set trading prices (Research Question 4)}

\subsubsection{Individual trait differences}

Participants' political orientation, place attachment, and climate change beliefs impacted their set trading prices as a function of the trading actor at hand. Whereas we could not observe a main effect of political orientation $(F(1,870)=3.38, p=.066)$, participants' political orientation impacted selling decisions depending on the involved trading actor $(F(5,4350)=12.82, p<.001)$. Please refer to Supplementary Table 8 for complete results. In line with the value foundations of left and right political orientations, participants with a more pronounced left political orientation were more likely to demand higher selling prices from multinational companies $\left(\right.$ Est $\left._{B}=-0.29, t=-3.38,95 \% \mathrm{CI}[-0.46,-0.12], p<.001\right)$ and were more likely to grant higher discounts to low-income households ( $E s t_{B}=0.34, t=4.74,95 \%$ CI[0.20,0.49], $p<.001)$ compared to participants with a more pronounced right orientation (see Figure 4A). In the selling condition, a more pronounced left orientation was related to higher discounts for friends and family $\left(E s t_{B}=0.20, t=2.70,95 \% \mathrm{CI}[0.05,0.34], p=.007\right)$, whereas political orientation did not influence selling decisions with small businesses, schools and hospitals, and neighbours (See Supplementary Tables 9-14 for complete selling results for each actor). Moreover, participants' political orientation impacted buying decisions depending on the trading actor at hand $(F(5,4350)=2.85, p=.014)$. Please refer to Supplementary Table 15 for complete results. In line with the results in the selling condition, participants with a more pronounced left orientation were more willing to pay more for electricity from low income households $\left(E s t_{B}=-0.20, t=-2.69,95 \% \mathrm{CI}[-0.35,-0.05], p=.007\right.$; see Figure 4B). See Supplementary Tables 16-21 for complete buying results for each actor.

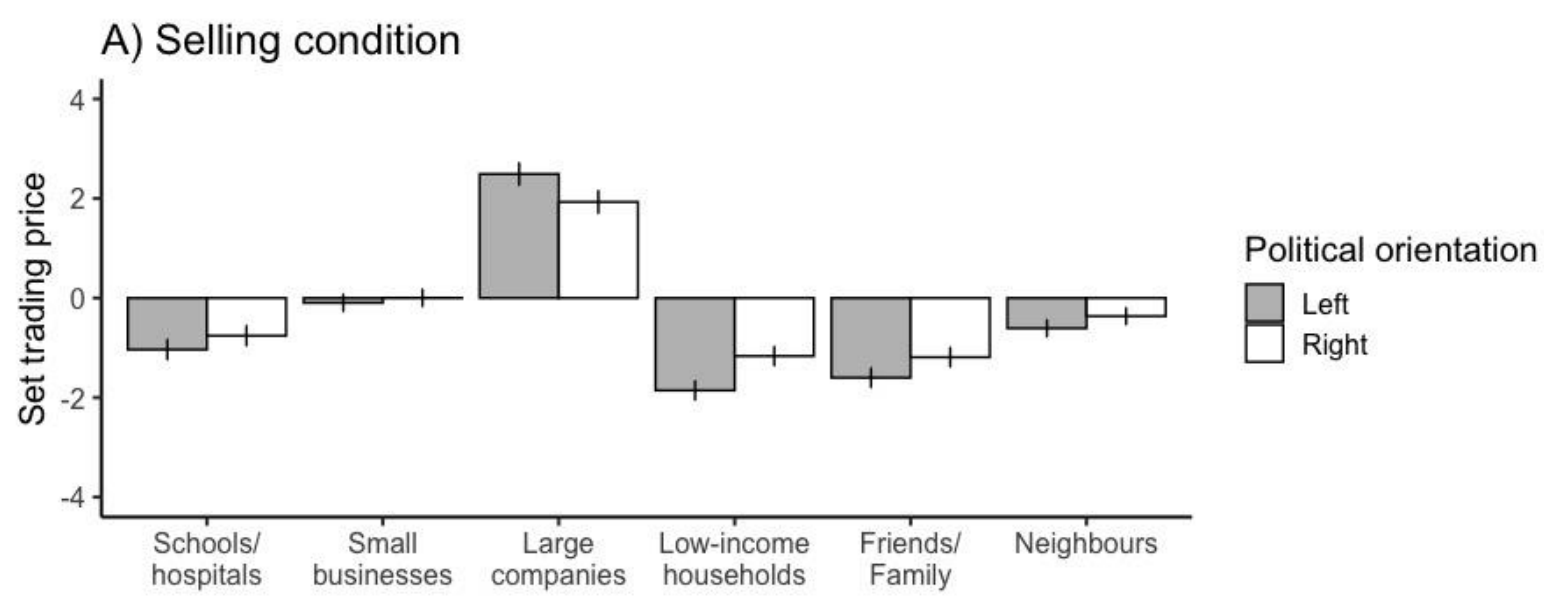




\section{B) Buying condition}

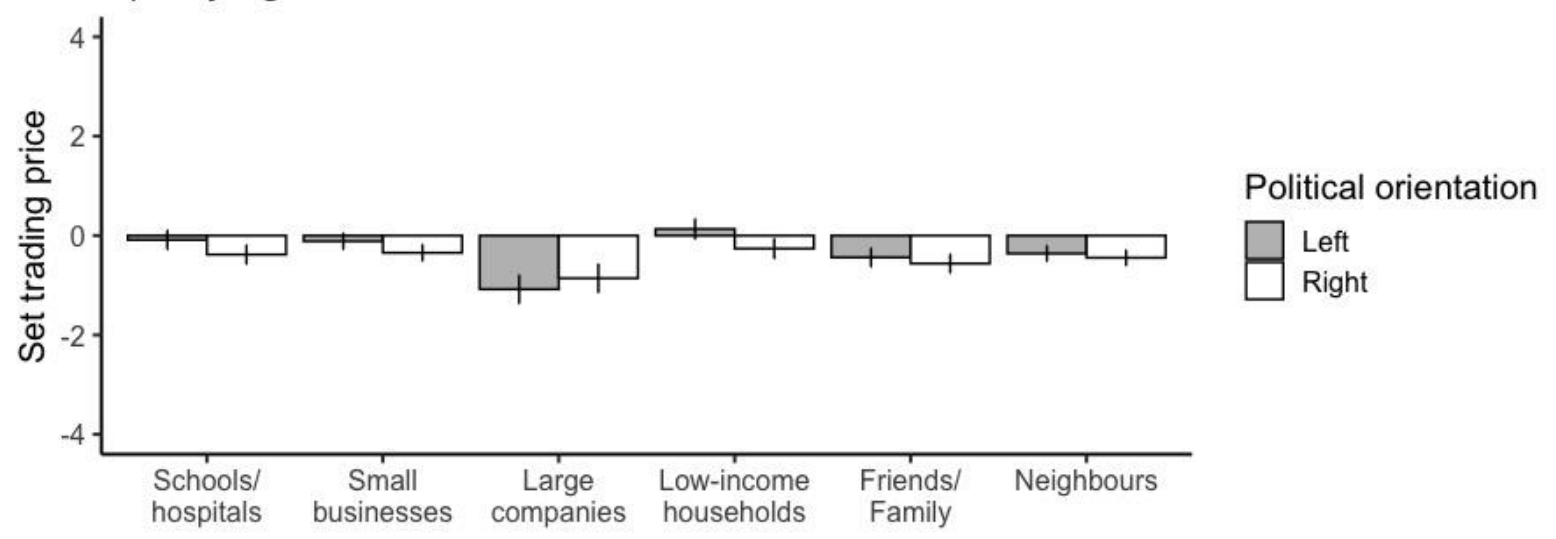

Figure 4. Set selling prices A) and buying prices B) as a function of trading actor and reported political orientation. Values on the $y$-axis refer to differences in $€ /$ Cent (German sample) and pence (UK sample) from the default electricity price. Predicted prices individually calculated for each actor are presented. Left and right political orientation refer to -1SD and +1SD from the mean, respectively. Error bars depict $95 \%$ confidence intervals.

Place attachment influenced selling decisions as a function of involved trading actor in that participants with stronger place attachment were more likely to grant discount to local stakeholders, including neighbours $\left(E t_{B}=-0.29, t=-4.75,95 \% \mathrm{CI}[-0.41,-0.17], p<.001\right)$, hospitals and schools $\left(E s t_{B}=-0.20, t=-2.69,95 \% \mathrm{CI}[-0.34,-0.05], p=.007\right)$, small businesses $\left(\right.$ Est $\left._{B}=-0.14, t=-2.31,95 \% \mathrm{CI}[-0.27,-0.02], p=.021\right)$, and low income households $\left(\right.$ Est $_{B}=-0.14$, $t=-2.05,95 \% \mathrm{CI}[-0.27,-0.01], p=.041)$. In contrast, place attachment did not influence buying conditions as neither a main effect $(F(1,870)=1.03, p=.311)$ nor an interaction with actor $(F(5,4350)=1.24, p=.288)$ could have been observed. See Supplementary Material for the influence of place attachment for each actor separately in the selling (SM Tables 9-14) and buying condition (SM Table 16-21).

Climate change beliefs impacted trading decisions as a function of trading actor $(F(1,870)=2.90, p=.013)$. In line with research illustrating that environmental and altruistic motives are strongly interlinked [46,47], participants with more pronounced climate change beliefs were more likely to grant selling discounts for schools and hospitals $\left(E s t_{B}=0.18, t=-\right.$ 2.26, 95\% CI[-0.338,-0.023], $p=.024)$ and low income households (Est $t_{B}=-0.15, t=-2.03,95 \%$ CI[-0.30, -0.00], $p=.043)$. Finally, climate change beliefs impacted buying decisions as a function of actor $(F(5,4350)=4.72, p<.001)$ in that participants with more pronounced climate change beliefs offered lower buying prices to large multinational companies compared to participants with less pronounced climate change beliefs (Est $t_{B}=-0.28, t=-2.49,95 \% \mathrm{CI}[-$ 
$0.49,-0.06], p=.013)$. See Supplementary Material for the influence of climate change belief for each actor separately in the selling (SM Tables 9-14) and buying condition (SM Table 1621).

\subsubsection{Individual differences in actor-specific trust}

As illustrated in Figure 5, reported trust significantly varied across actors $(F(5,4405)=612.37$, $p<.001)$. Except for neighbours and small businesses, reported trust levels significantly differed between all actors. See Supplementary Table 22 for all differences.

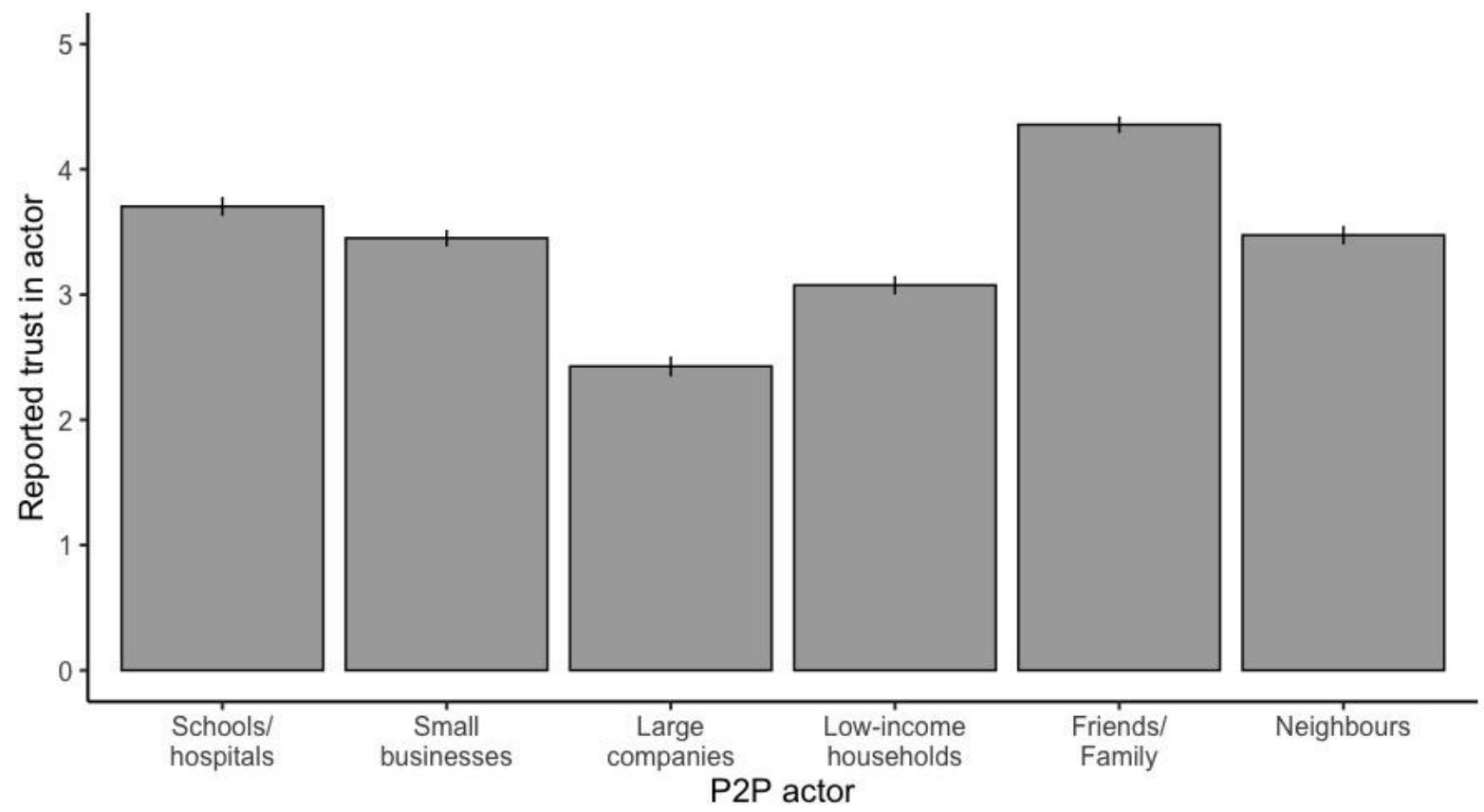

Figure 5. Reported trust in the involved actors in the P2P community. Higher values on the y-axis refer to higher reported trust. All differences, except of neighbours-small businesses are statistically significant $(p<.001)$. Error bars depict $95 \%$ confidence intervals.

Analysis of the impact of trust on selling preferences revealed that higher trust in a given trading actor resulted in lower set selling prices $(F(1,5136)=197.38, p<.001)$. As illustrated in Figure $6 \mathrm{~A}$, the influence of trust on selling prices varied between trading actors $(F(1,4559)=3.56, p=.003)$. Trust most strongly impacted selling decisions when participants traded with friends and family $\left(E_{s} t_{B}=-0.65, t=-7.06,95 \% \mathrm{CI}[-0.84,-0.47], p<.001\right)$ and this influence was stronger compared to when participants traded with neighbours $\left(\right.$ Est $_{B}=0.22$, $t=2.26,95 \% \mathrm{CI}[0.03,0.41], p=.024)$ and low-income households $\left(E_{s} t_{B}=0.24, t=-7.06,95 \%\right.$ $\mathrm{CI}[0.05,0.44], p=.013)$ and marginally stronger compared to small business $\left(\right.$ Est $_{B}=0.19$, $t=1.89,95 \% \mathrm{CI}[-0.01,0.39], p=.059)$, but not compared to multinational businesses Est $_{B}=-$ $0.05, t=-0.50,95 \% \mathrm{CI}[-0.24,0.14], p=.618)$ and schools/hospitals $E t_{B}=0.10, t=0.10,95 \%$ 
CI[-0.09,0.29], $p=.319)$. See Supplementary Tables 23-28 for the influence of trust on set selling prices for each actor separately.

Trust also impacted buying decisions $(F(1,5204)=23.15, p<.001)$ and the influence of trust on buying decisions varied between actors $(F(1,4612)=3.15, p=.008)$. As illustrated in Figure 6B, trust most strongly impacted buying decisions when participants traded with multinational companies $\left(E_{s t_{B}}=0.46, t=4.21,95 \% \mathrm{CI}[0.240 .67], p<.001\right)$ and this influence was stronger compared to when participants traded with small business $\left(\right.$ Est $_{B}=-0.30, t=-2.90$, 95\% CI[-0.50,-0.10], $p=.004)$, low-income families $\left(E_{s} t_{B}=-0.26, t=-2.71,95 \%\right.$ CI[-0.45, $0.07], p=.007)$, friends and family $\left(E s t_{B}=-0.32, t=-3.07,95 \% \mathrm{CI}[-0.53,-0.12], p=.002\right)$, and neighbours $\left(\right.$ Est $\left._{B}=-0.31, t=-3.21,95 \% \mathrm{CI}[-0.50,-0.12], p=.001\right)$ and marginally stronger compared to hospitals and schools $\left(E s t_{B}=-0.18, t=-1.86,95 \% \mathrm{CI}[-0.37,0.01], p=.062\right)$. See Supplementary Tables 29-34 for the influence of trust on set buying prices for each actor separately.

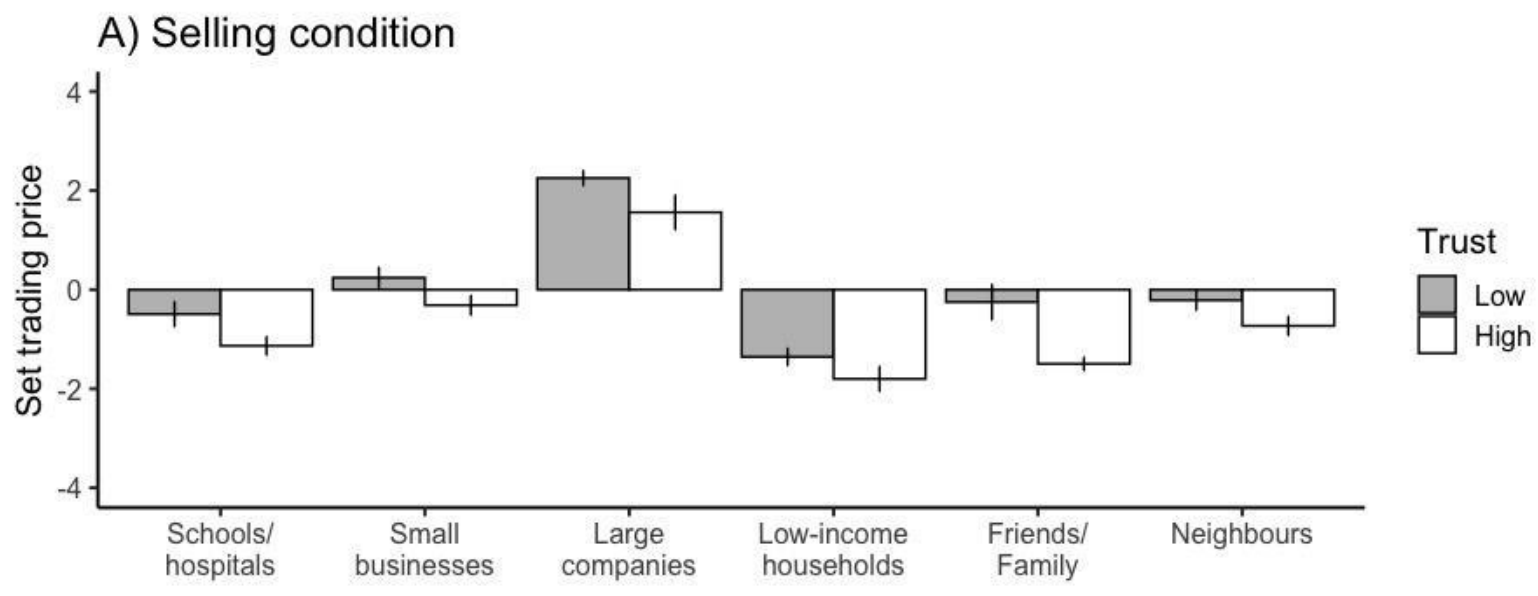

B) Buying condition

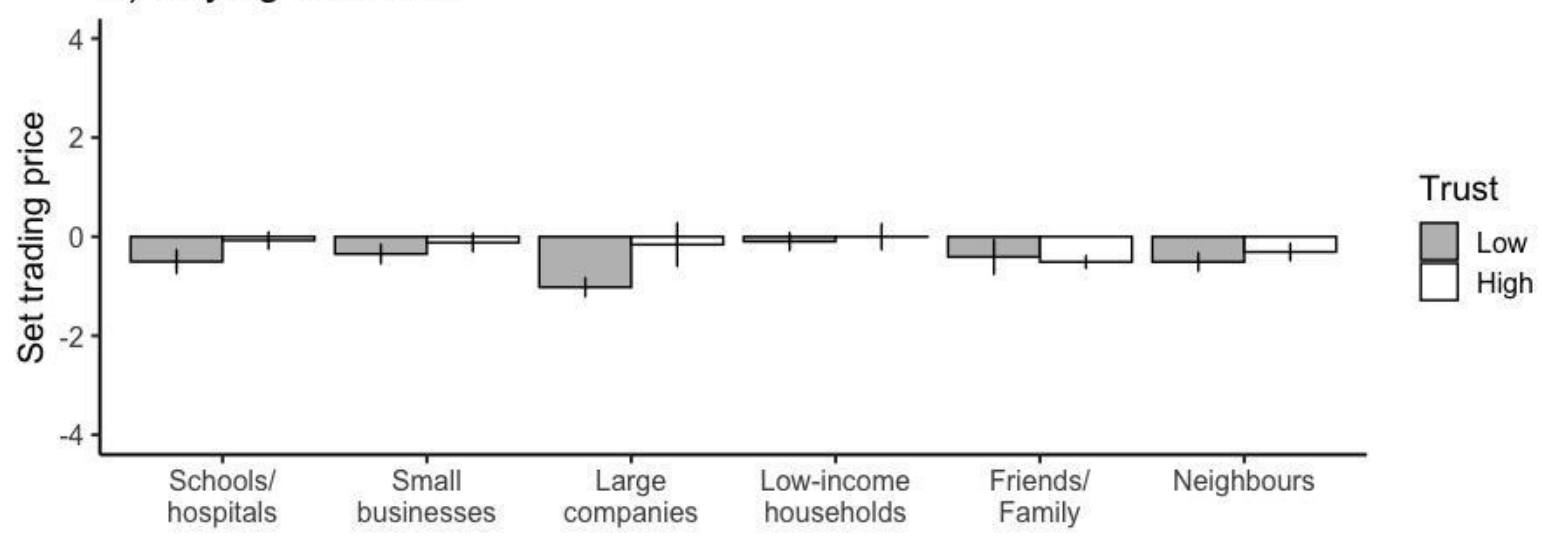


Figure 6. Set selling prices A) and buying prices B) as a function of actor and reported trust towards a given actor. Values on the $y$-axis refer to differences in $€ /$ Cent (German sample) and pence (UK sample) from the default electricity price. Trust was z-standardized across all actors before the analysis. Error bars depict $95 \%$ confidence intervals.

\subsection{Discussion}

In the present multinational, preregistered study, we investigated $\mathrm{P} 2 \mathrm{P}$ trading decisions and the underlying factors in a prosumer-centred peer-to-peer electricity community with various private and non-private actors. Our results show that people do indeed set different trading price preferences with different community actors. Most of this variance stems from changes in the selling price that people choose to set, with a combination of relatively deep discounts and steep premiums. Whether trading preferences were made in private or were publicly visible did not impact trading decisions overall. There was, however, variation between countries, with UK participants offering and asking for smaller discounts when decisions were made public. Finally, our findings demonstrate that interindividual differences in political orientation, place attachment and climate change beliefs as well as differences in actor-specific trust are underlying drivers of trading decisions.

In this section we first discuss what we view as the main limitations of this study, and how generalisable we consider the findings to be. Having set out this foundation, we then share our interpretation of the results.

\subsection{Limitations}

The main limitation of this study is the hypothetical nature of the scenario. Results based on stated preferences may vary from real-world behaviours (but see also recent findings on the ecological validity of stated preferences $[51,52])$. This could be for a range of reasons, including people's inability to accurately judge how they would choose to act in a situation (especially an unfamiliar one), social desirability bias [53], and external factors which prevent people from expressing their preferred actions or decisions. To mitigate this we took steps to maximise the ecological validity of the price-setting scenario. The measures encompass that participants had the opportunity to set default prices that then, in turn, could be administered by a trading algorithm in everyday life. As discussed recently, this default setting could actually be a realistic option to implement individual $\mathrm{P} 2 \mathrm{P}$ price setting preferences in future P2P communities by concomitantly reducing user workload [54]. 
Despite the benefits of our cross-national comparison, a further limitation attaches to the conduct of the study in two countries simultaneously. This required administering the survey in two languages, and using two different currencies. Any influence of currency could come as a result of two factors - the incremental value of one Euro cent compared to one pence (the former is worth approximately $90 \%$ of the latter), and the relative impact of a cent/pence discount or premium on the average unit price in Germany or the UK. Because of the higher price of electricity in Germany (approximately twice as high as in the UK), the relative impact of adding or subtracting one Euro Cent in Germany compared to one pence in the UK is lower. Given the broadly similar results obtained in the two countries, we believe that relative prices (compared to absolute prices) to have had little impact on the findings.

\subsection{Generalisability}

While conducting this study simultaneously in two countries introduced the challenges highlighted above, it also brought with it benefits for generalisability. The reproduction of many of the findings in two completely independent samples in different national contexts suggests that the findings are likely also to be relevant in other countries with similar societal and energy system characteristics, such as most European Union countries. However, we call for future research that systematically examines differences in trading decisions and strategies across nations, ideally encompassing multiple nations in order to examine the impact of nation-level variables on individual decision-making.

Another important consideration for the generalisability of this study was its conduct in the midst of the Covid-19 pandemic [55]. At the time of study deployment in December 2020, both the UK and Germany were experiencing regional restrictions on citizens' freedom to move and associate. The pandemic has also brought with it increasing contact or even reliance on neighbours by some for services such as collecting food and medicines. Such considerations could have some bearing on the extent to which people believed altruistic behaviour was merited. These factors should be taken as important context in considering how far the results we received might be applicable in the years to come. See Supplementary Note 2 for information on perceived effects of the pandemic reported in our samples.

\subsection{Interpretation}

Given the above considerations we draw a number of interpretations of our findings. There are a range of possible explanations for the larger willingness to offer discounts on selling 
prices and to offer premiums on buying prices. Given the typical size of domestic solar installations, the quantity of excess power sold is likely to be relatively small compared to the amount which is purchased. Participants who considered this may therefore have been more willing to show movement in their selling prices, expecting the absolute impact of this to be relatively small. It may also have been connected with loss aversion, where people place greater value on losses than gains of an equivalent magnitude [56]. Because the decision task was framed around excess generation, discounting sale of this may be framed as a smaller gain, rather than a loss - as would be the case for paying more for power.

Our analysis points to three different trading strategies that participants applied, depending on the trading actor at hand. Specifically, we observed tit-for-tat pricing with neighbours and local small businesses, altruistic pricing with friends and family, local schools and hospitals, and local low-income households, and noncooperative pricing for large companies. Our analysis further showed that trust was a strong underlying driver of altruistic trading patterns, but of less relevance for tit-for-tat trading patterns where discounts were relatively low. That is, participants not only reported high levels of trust for friends/family and schools, but also integrated trust appraisals in their decisions to a larger extent when they traded with those groups. Correspondingly, offered discounts were among the highest for those groups. Interindividual differences in trust, however, could not explain altruistic trading with lowincome families, who received overall the highest discounts. These findings indicate a difference in operation between altruistic behaviour reflecting an expression and acknowledgement of social ties and altruistic behaviour reflecting perceived need. Given the previous evidence of reluctance to engage in financial transactions with close personal acquaintances [18], in the absence of ability to avoid it, altruistic trading may be seen as the next best possible strategy.

Noncooperative trading patterns were further shaped by participants' political orientation in that participants with a more pronounced left political orientation were more likely to charge a higher premium to multinational companies. This trading pattern can be associated with variation in market and system justification beliefs along the left-right political spectrum $[42,43]$. More specifically, a more pronounced right political orientation has been linked with stronger beliefs that market and economic processes are inherently fair and do not require significant regulations [42]. Demanding lower selling prices from multinational companies aligns with such beliefs. Our findings moreover corroborate research showing that political 
conservatism is associated with more tolerance for social inequality [57]. In accordance, in our study a more pronounced right political orientation was associated with a lower willingness to offer discounts and to charge a lower premium to low-income households compared to a more pronounced left political orientation.

Participants who expressed more concern about climate change were similarly more likely to offer discounts to low-income households, and schools/hospitals. This is consistent with previous research linking environmental and altruistic concerns [46,47]. Future research, separating environmental and altruistic interindividual differences can help to disentangle the influence of environmental and altruistic drivers of trading decisions in PCM.

Furthermore, higher place attachment was associated with willingness to offer higher discounts to local actors. Such an offer of discount can be interpreted as an affirmation of solidarity with the locality and its residents and services. These findings also broadly accord with work by [6] who found that prosumers who were energy cooperative members were less motivated by personal economic gain than non-members in their stated trading preferences.

Our findings did not indicate an overall impact of public visibility of trading preferences on set trading prices. However, this does mask a modest inter-country difference. While UK and Germany participants set similar buying and selling prices when trading preferences were private, they diverged when preferences were framed as publicly visible. German participants' preferences did not change, but UK participants offered, and requested, smaller discounts when their trading decisions were public. This finding illustrates the importance to consider heterogeneity across contexts and populations in the analysis of human decisionmaking as well as in the design of decision environments [58]. Making decisions public thus cannot be seen as a universal strategy to stimulate more generous trading prices, but can even result in inverse effects, depending on where the intervention is implemented. Our findings extend previous research on the role of public visibility in promoting prosocial behaviour, emphasising the need to consider the context in which decisions are made in order to make accurate predictions of visibility effects [59].

\subsection{Conclusions and implications}

This study tested whether people set different buying and selling prices with different actor groups in a hypothetical prosumer-centred peer-to-peer electricity trading scheme. Our results 
from German and UK samples revealed that variation occurs in the level of discount offered on electricity sales to different actors. Variation in buying price was relatively limited, with no actor offered a premium above the average electricity price, and a substantial discount requested only from larger multinational companies. Making trading preferences publicly visible impacted decisions depending on national context, with UK participants offering and asking for smaller discounts in the publicly visible condition. We identified psychological factors that underlie different trading preferences.

If our results were to be borne out in practice, they suggest there is potential for modest bill savings for some actors, particularly public services such as schools/hospitals, low-income households, and the friends/family of participating prosumers. These savings are subsidised by the prosumers themselves. This finding has implications for energy justice and may offer new pathways to provide specific groups such as low-income families access to renewable energy at lower prices [60-62]. However, actor-specific price definitions also increase the risk that discriminatory pricing practices arise, as has been observed for factors such as race and ethnicity in the P2P accommodation service Airbnb [63]. These potential risks and benefits for energy justice need to be examined in future research in order to develop PCM that allow for affordable clean energy access without discriminating against certain group members.

Our findings indicate these savings would be more marked in areas where there are more politically left-leaning citizens, or with greater place attachment, or more concern about climate change. This suggests the ability to save money as a consumer in PCM such as P2P energy trading could be driven by who you know (your friends and family) and the ideological makeup of the place you live. However, the scale of discounts offered, combined with the relatively small proportion of electricity that PCMs are likely to account for (at least initially) means bill impacts are likely to be modest. However, it is possible that changes in the ways that actors are grouped and framed could amplify these impacts, as we observed for trading preference visibility in the UK.

Our findings have relevance for energy policy and regulation. Currently, countries with mature electricity systems generally require that electricity tariffs are made available on an equal basis to all customers, at least within a given region (as a result of universal service obligations). Targeting member-specific discounts in PCMs is not really compatible with this. 
Policymakers and regulators will need to balance the desire to promote innovation in support of net-zero carbon ambitions against the risk of amplifying inequalities. While our results show a willingness to subsidise services and households in need, policymakers must also consider the extent to which it is desirable for such subsidies to be delivered via the means of electricity bills at the discretion of individual prosumers, rather than socialised across all billor tax-payers. This mirrors debates around the relative merits of charity and taxation - the former providing donors an option to support causes of their choice, while risking that less visible but still important causes go underfunded.

Our results also suggest implications for stakeholders implementing PCMs. Our findings emphasise that distributional impacts are a potential outcome, and that this should therefore be considered in PCM design. There is no obvious best way forward, as less targeted alternatives (e.g. where discounts are shared between all participants) will likely reward higher electricity users the most, as their higher demand would lead to them accessing more of the excess cheaper-rate power. This will likely be highly dependent on local factors and goals. However, giving explicit consideration to this possibility and making sure it is clear in participatory planning processes would ensure it is taken into account and can be monitored.

Our findings suggest a number of avenues for future research. In common with most stated preference-based research, it will be important to observe the extent to which our findings are replicated in real-world trials of similar services and, in the case of differences, explore the reasons for this. Our findings may also usefully inform user-centered PCM community modelling that attempts to integrate actual individual decision-making preferences to make more accurate predictions of community performance [54]. Our observation of inter-country differences reinforces the importance of recognising contextual heterogeneity in studies of behaviour [58]. This is likely to be particularly important where PCMs are proliferating in a highly atomised way across countries, and we need to rapidly learn what works best in different contexts. Where possible, conducting multi-regional studies (or conducting studies in transparent and consistent ways) so as to allow comparison will help shed light on which outcomes are most robust to contextual differences, and which are more dependent on them. Application of realist approaches to research, which explore "what works, for whom, in what circumstances, how and why?" [64] are likely to be particularly useful. 


\section{Author contributions}

Conceptualization: U.J.J. \& M.J.F.; Data curation: U.J.J.; Formal analysis: U.J.J.; Funding acquisition: M.J.F.; Investigation : U.J.J. \& M.J.F.; Methodology: U.J.J. \& M.J.F.; Visualization : U.J.J.; Roles/Writing - original draft : U.J.J. \& M.J.F.; Writing - review \& editing: U.J.J. \& M.J.F.

\section{Acknowledgements}

The research is part of the activities of SCCER CREST, which is financially supported by the Swiss Innovation Agency - Innosuisse. We gratefully acknowledge support from UK Research and Innovation through the Centre for Research into Energy Demand Solutions, grant reference number EP/R035288/1. The funding sources had no involvement in the preparation of the article, in the study design, the collection, analysis and interpretation of data, nor in the writing of the manuscript. We are grateful to Laura Pagel for her support in developing the study material and in collecting the cross-national data.

\section{Data availability statement}

The data that support the findings of this study, along with the analysis code, are openly available in the Open Science Framework (OSF) at: [to be shared upon journal publication]. Further details relevant to the transparency, reproducibility and quality of reporting of this study are presented in Supplementary Table 35 [65].

\section{References}

[1] Sousa T, Soares T, Pinson P, Moret F, Baroche T, Sorin E. Peer-to-peer and community-based markets: A comprehensive review. Renew Sustain Energy Rev 2019;104:367-78. https://doi.org/10.1016/J.RSER.2019.01.036.

[2] Marzal S, Salas R, González-Medina R, Garcerá G, Figueres E. Current challenges and future trends in the field of communication architectures for microgrids. Renew Sustain Energy Rev 2018;82:3610-22. https://doi.org/10.1016/J.RSER.2017.10.101.

[3] Guerrero J, Gebbran D, Mhanna S, Chapman AC, Verbič G. Towards a transactive energy system for integration of distributed energy resources: Home energy management, distributed optimal power flow, and peer-to-peer energy trading. Renew Sustain Energy Rev 2020;132:110000. https://doi.org/10.1016/J.RSER.2020.110000. 
[4] Tsao YC, Thanh V Van. Toward sustainable microgrids with blockchain technologybased peer-to-peer energy trading mechanism: A fuzzy meta-heuristic approach. Renew Sustain Energy Rev 2021;136:110452. https://doi.org/10.1016/J.RSER.2020.110452.

[5] Vieira G, Zhang J. Peer-to-peer energy trading in a microgrid leveraged by smart contracts. Renew Sustain Energy Rev 2021;143:110900. https://doi.org/10.1016/J.RSER.2021.110900.

[6] Georgarakis E, Bauwens T, Pronk AM, AlSkaif T. Keep it green, simple and socially fair: A choice experiment on prosumers' preferences for peer-to-peer electricity trading in the Netherlands. Energy Policy 2021;159:112615. https://doi.org/10.1016/J.ENPOL.2021.112615.

[7] Tushar W, Saha TK, Yuen C, Morstyn T, McCulloch MD, Poor HV, et al. A motivational game-theoretic approach for peer-to-peer energy trading in the smart grid. Appl Energy 2019;243:10-20. https://doi.org/10.1016/j.apenergy.2019.03.111.

[8] Ecker F, Spada H, Hahnel UJJ. Independence without control: Autarky outperforms autonomy benefits in the adoption of private energy storage systems. Energy Policy 2018;122. https://doi.org/10.1016/j.enpol.2018.07.028.

[9] Hahnel UJJ, Herberz M, Pena-Bello A, Parra D, Brosch T. Becoming prosumer: Revealing trading preferences and decision-making strategies in peer-to-peer energy communities. Energy Policy 2020;137:1-11. https://doi.org/https://doi.org/10.1016/j.enpol.2019.111098.

[10] Schulz KF, Altman DG, Moher D. CONSORT 2010 Statement: updated guidelines for reporting parallel group randomised trials. BMJ 2010;340:c332-c332. https://doi.org/10.1136/bmj.c332.

[11] Cyrus C, Wait R. Best Green Energy Suppliers Of 2021. Forbes 2021. https://www.forbes.com/uk/advisor/energy/greenenergy/\#guide_to_green_energy_section (accessed December 2, 2021).

[12] Ambrose J. How green is your "green" energy tariff? Guard 2021. https://www.theguardian.com/business/2021/apr/02/green-energy-tariff-renewabledeals (accessed November 29, 2021).

[13] Hackbarth A, Löbbe S. Attitudes, preferences, and intentions of German households concerning participation in peer-to-peer electricity trading. Energy Policy 2020;138:111238. https://doi.org/10.1016/J.ENPOL.2020.111238.

[14] Reuter E, Loock M. Empowering Local Electricity Markets- A survey study from 
Switzerland, Norway, Spain and Germany. University of St. Gallen; 2017.

[15] Fell MJ, Schneiders A, Shipworth D. Consumer Demand for Blockchain-Enabled Peerto-Peer Electricity Trading in the United Kingdom: An Online Survey Experiment. Energies 2019;12:3913. https://doi.org/10.3390/en12203913.

[16] Mengelkamp E, Schönland T, Huber J, Weinhardt C. The value of local electricity - A choice experiment among German residential customers. Energy Policy 2019;130:294303. https://doi.org/10.1016/J.ENPOL.2019.04.008.

[17] Wörner AM, Ableitner L, Meeuw A, Wortmann F, Tiefenbeck V. Peer-to-Peer Energy Trading in the Real World: Market Design and Evaluation of the User Value Proposition 2019. https://doi.org/10.3929/ETHZ-B-000395174.

[18] Pumphrey K, Walker SL, Andoni M, Robu V. Green hope or red herring? Examining consumer perceptions of peer-to-peer energy trading in the United Kingdom. Energy Res Soc Sci 2020;68:101603. https://doi.org/10.1016/j.erss.2020.101603.

[19] Scuri S, Tasheva G, Barros L, Nunes NJ. An HCI Perspective on Distributed Ledger Technologies for Peer-to-Peer Energy Trading. Lect Notes Comput Sci (Including Subser Lect Notes Artif Intell Lect Notes Bioinformatics) 2019;11748 LNCS:91-111. https://doi.org/10.1007/978-3-030-29387-1_6.

[20] Singh A, Strating AT, Romero Herrera NA, Mahato D, Keyson D V, van Dijk HW. Exploring peer-to-peer returns in off-grid renewable energy systems in rural India: An anthropological perspective on local energy sharing and trading. Energy Res Soc Sci 2018;46:194-213. https://doi.org/10.1016/j.erss.2018.07.021.

[21] Wilkinson S, Hojckova K, Eon C, Morrison GM, Sandén B. Is peer-to-peer electricity trading empowering users? Evidence on motivations and roles in a prosumer business model trial in Australia. Energy Res Soc Sci 2020;66:101500. https://doi.org/10.1016/j.erss.2020.101500.

[22] Wilkins DJ, Chitchyan R, Levine M. Peer-to-Peer Energy Markets: Understanding the Values of Collective and Community Trading, Association for Computing Machinery; 2020, p. 1-14. https://doi.org/10.1145/3313831.3376135.

[23] Smale R, Kloppenburg S. Platforms in Power: Householder Perspectives on the Social, Environmental and Economic Challenges of Energy Platforms. Sustainability 2020;12:692. https://doi.org/10.3390/su12020692.

[24] Reindl K, Palm J. Installing PV: Barriers and enablers experienced by non-residential property owners. Renew Sustain Energy Rev 2021;141:110829. https://doi.org/10.1016/J.RSER.2021.110829. 
[25] Ableitner L, Tiefenbeck V, Meeuw A, Wörner A, Fleisch E, Wortmann F. User behavior in a real-world peer-to-peer electricity market. Appl Energy 2020;270:115061. https://doi.org/10.1016/J.APENERGY.2020.115061.

[26] Nowak MA. Five rules for the evolution of cooperation. Science (80- ) 2006;314:1560. https://doi.org/10.1126/SCIENCE.1133755.

[27] Hilbe C, Chatterjee K, Nowak MA. Partners and rivals in direct reciprocity. Nat Hum Behav 2018;2:469-77. https://doi.org/10.1038/s41562-018-0320-9.

[28] Fowler JH. Altruistic punishment and the origin of cooperation. Proc Natl Acad Sci 2005;102:7047-9. https://doi.org/10.1073/PNAS.0500938102.

[29] Fehr E, Fischbacher U. The nature of human altruism. Nat 20034256960 2003;425:785-91. https://doi.org/10.1038/nature02043.

[30] Mayer RC, Davis JH, Schoorman FD. An Integrative Model Of Organizational Trust. Acad Manag Rev 1995;20:709-34. https://doi.org/10.5465/AMR.1995.9508080335.

[31] Stenner K, Frederiks ER, Hobman E V., Cook S. Willingness to participate in direct load control: The role of consumer distrust. Appl Energy 2017;189:76-88. https://doi.org/10.1016/J.APENERGY.2016.10.099.

[32] Fell MJ, Shipworth D, Huebner GM, Elwell CA. Knowing Me, Knowing You: The role of trust, locus of control and privacy concern in acceptance of domestic electricity demand-side response. ECEEE 2015 Summer Study Proc. Study Proc., Presqu'île de Giens, France: 2015, p. 2153-63.

[33] Ariely D, Bracha A, Meier S. Doing Good or Doing Well? Image Motivation and Monetary Incentives in Behaving Prosocially. Am Econ Rev 2009;99:544-55. https://doi.org/10.1257/aer.99.1.544.

[34] Andreoni J, Petrie R. Public goods experiments without confidentiality: a glimpse into fund-raising. J Public Econ 2004;88:1605-23. https://doi.org/10.1016/S00472727(03)00040-9.

[35] Connelly BL, Certo ST, Ireland RD, Reutzel CR. Signaling Theory: A Review and Assessment: Https://DoiOrg/101177/0149206310388419 2010;37:39-67. https://doi.org/10.1177/0149206310388419.

[36] Panchanathan K, Boyd R. Indirect reciprocity can stabilize cooperation without the second-order free rider problem. Nat 20044327016 2004;432:499-502. https://doi.org/10.1038/nature02978.

[37] Nicolson M, Lotti L. Democratising the energy market : applying behavioural game theory to peer-to-peer electricity trading markets Democratising the energy market : 
applying behavioural game theory to peer-to- peer electricity trading markets. Polit Stud Assoc Annu Int Conf 20182018.

[38] Henrich J, Ensminger J, McElreath R, Barr A, Barrett C, Bolyanatz A, et al. Markets, religion, community size, and the evolution of fairness and punishment. Science (80- ) 2010;327:1480-4. https://doi.org/10.1126/SCIENCE.1182238/SUPPL_FILE/HENRICH.SOM.PDF.

[39] Henrich J, McElreath R, Barr A, Ensminger J, Barrett C, Bolyanatz A, et al. Costly punishment across human societies. Science (80- ) 2006;312:1767-70. https://doi.org/10.1126/science.1127333.

[40] Herrmann B, Thöni C, Gächter S. Antisocial Punishment Across Societies. Science (80- ) 2008;319:1362-7.

[41] Carrus G, Scopelliti M, Fornara F, Bonnes M, Bonaiuto M. Place attachment, community identification, and pro-environmental engagement. Place Attach Adv Theory, Methods Appl n.d.:154-64.

[42] Jost JT, Hunyady O. Antecedents and Consequences of System-Justifying Ideologies: Curr Dir Psychol Sci 2005;14:260-5. https://doi.org/10.1111/J.09637214.2005.00377.X.

[43] Jost JT, Federico CM, Napier JL. Political Ideology: Its Structure, Functions, and Elective Affinities. Annu Rev Psychol 2008;60:307-37. https://doi.org/10.1146/ANNUREV.PSYCH.60.110707.163600.

[44] F.G. Reis I, Gonçalves I, A.R. Lopes M, Henggeler Antunes C. Business models for energy communities: A review of key issues and trends. Renew Sustain Energy Rev 2021;144:111013. https://doi.org/10.1016/J.RSER.2021.111013.

[45] Lowitzsch J, Hoicka CE, van Tulder FJ. Renewable energy communities under the 2019 European Clean Energy Package - Governance model for the energy clusters of the future? Renew Sustain Energy Rev 2020;122:109489. https://doi.org/10.1016/J.RSER.2019.109489.

[46] Schwartz SH, Cieciuch J, Vecchione M, Davidov E, Fischer R, Beierlein C, et al. Refining the theory of basic individual values. J Pers Soc Psychol 2012;103:663-88. https://doi.org/10.1037/A0029393.

[47] Conte B, Hahnel UJJ, Brosch T. The dynamics of humanistic and biospheric altruism in conflicting choice environments. Pers Individ Dif 2021;173:110599. https://doi.org/10.1016/j.paid.2020.110599.

[48] Spence A, Poortinga W, Pidgeon N. The Psychological Distance of Climate Change. 
Risk Anal 2012;32:957-72. https://doi.org/10.1111/J.1539-6924.2011.01695.X.

[49] Raymond CM, Brown G, Weber D. The measurement of place attachment: Personal, community, and environmental connections. J Environ Psychol 2010;30:422-34. https://doi.org/10.1016/j.jenvp.2010.08.002.

[50] Williams DR, Vaske JJ. The Measurement of Place Attachment: Validity and Generalizability of a Psychometric Approach. For Sci 2003;49:830-40. https://doi.org/10.1093/forestscience/49.6.830.

[51] Hascher J, Desai N, Krajbich I. Incentivized and non-incentivized liking ratings outperform willingness-to-pay in predicting choice. Judgm Decis Mak 2021;16:146484.

[52] Mertens S, Herberz M, Hahnel UJJ, Brosch T. The effectiveness of nudging: A metaanalysis of choice architecture interventions across behavioral domains. Proc Natl Acad Sci U S A n.d.

[53] Nederhof AJ. Methods of coping with social desirability bias: A review. Eur J Soc Psychol 1985;15:263-80. https://doi.org/10.1002/EJSP.2420150303.

[54] Pena-Bello A, Parra D, Herberz M, Tiefenbeck V, Patel MK, Hahnel UJJ. Integration of prosumer peer-to-peer trading decisions into energy community modeling. Nat Energy. https://doi.org/10.1038/s41560-021-00950-2

[55] Fell MJ, Pagel L, Chen C fei, Goldberg MH, Herberz M, Huebner GM, et al. Validity of energy social research during and after COVID-19: challenges, considerations, and responses. Energy Res Soc Sci 2020;68:101646. https://doi.org/10.1016/j.erss.2020.101646.

[56] Kahneman D, Tversky A. Prospect Theory: An Analysis of Decision under Risk. Econometrica 1979;47:263. https://doi.org/10.2307/1914185.

[57] Jost JT, Glaser J, Kruglanski AW, Sulloway FJ. Political conservatism as motivated social cognition. Psychol Bull 2003;129:339-75.

[58] Bryan CJ, Tipton E, Yeager DS. Behavioural science is unlikely to change the world without a heterogeneity revolution. Nat Hum Behav 2021;5:980-9. https://doi.org/10.1038/s41562-021-01143-3.

[59] Kafashan S, Sparks A, Griskevicius V, Barclay P. Prosocial Behavior and Social Status. In: Cheng J, Tracy J, Anderson C, editors. Psychol. Soc. Status, Springer, New York, NY; 2014, p. 139-58. https://doi.org/10.1007/978-1-4939-0867-7_7.

[60] Sovacool BK, Dworkin MH. Energy justice: Conceptual insights and practical applications. Appl Energy 2015;142:435-44. 
https://doi.org/10.1016/J.APENERGY.2015.01.002.

[61] Jenkins K, McCauley D, Heffron R, Stephan H, Rehner R. Energy justice: A conceptual review. Energy Res Soc Sci 2016;11:174-82. https://doi.org/10.1016/J.ERSS.2015.10.004.

[62] Adams S, Brown D, Pablo J, Chitchyan R, Fell MJ, Hahnel UJJ, et al. Social and Economic Value in Emerging Decentralized Energy Business Models : A Critical Review. Energies 2021;14:1-29.

[63] Fell MJ. Anticipating distributional impacts of peer-to-peer energy trading: Inference from a realist review of evidence on Airbnb. Clean Responsible Consum 2021;2:100013. https://doi.org/10.1016/j.clrc.2021.100013.

[64] Wong G, Greenhalgh T, Westhorp G, Buckingham J, Pawson R. RAMESES publication standards: Realist syntheses. BMC Med 2013;11:1-14. https://doi.org/10.1186/1741-7015-11-21/FIGURES/1.

[65] Huebner GM, Fell MJ, Watson NE. Improving energy research practices: guidance for transparency, reproducibility and quality. Build Cities 2021;2:1-20. https://doi.org/10.5334/bc.67. 


\section{Pricing decisions in peer-to-peer and prosumer-centred electricity markets: Experimental analysis in Germany and the United Kingdom}

-----Supplementary Material-----

Hahnel, U.J.J. ${ }^{1}$ and Fell, M.J. ${ }^{2}$

${ }^{1}$ Department of Psychology and Swiss Center for Affective Sciences, University of Geneva, Switzerland.

${ }^{2}$ UCL Energy Institute, University College London, UK

\section{Supplementary Notes}

\section{Supplementary Note 1: Additional information on P2P trading task}

As literacy about electricity prices and consumption tends to be low in the population, an information box was displayed in both conditions (i.e., buying and selling condition), informing participants that price changes of 1 to 5 pence $/ \mathrm{kWh}$ [€Cent $/ \mathrm{kWh}$ ] would result in a decrease/increase in annual electricity costs by 50 to 250 pounds [€] (considering an annual consumption of $5000 \mathrm{kWh}$ ). We also informed participants that depending on the price they set, the groups might choose to trade electricity with someone else. That is, asking for higher discounts in the buying condition and higher price premium in the selling condition would decrease the likelihood that the groups accept the offer, whereas offering higher price premium and higher discounts in the selling condition would increase the likelihood that the groups accept the offer. We finally considered ancillary costs (e.g., network costs) and informed participants that the set maximum discount (-5pence [€Cent]) would not result in any revenue from the sale for the respective selling actor, but would only cover external costs. 


\section{Supplementary Note 2: Impact of the COVID-19 pandemic on generalisability}

Another important consideration for the generalisability of this study was its conduct in the midst of the Covid-19 pandemic. At the time of study deployment in December 2020, both the UK and Germany were experiencing regional restrictions on citizens' freedom to move and associate. In our sample around $80 \%$ of participants indicated that the pandemic had had a moderate to large impact on their daily lives, and just under $30 \%$ said they were financially worse off. We asked people about how negative an effect they thought the pandemic had in each subsample. Local hospitals, schools and shops were viewed as having fared particularly badly, with around $90 \%$ of people in each case viewing them as having been moderately to strongly negatively affected. The pandemic has also brought with it increasing contact or even reliance on neighbours by some for services such as collecting food and medicines. All of these considerations could have some bearing on the extent to which people believed altruistic behaviour was merited. These factors should be taken as important context in considering how far the results we received might be applicable in the years to come. 


\section{Supplementary Tables}

\section{RQ1: Supplementary Tables}

Supplementary Table 1: Multilevel model results on the price settings as a function of trading condition (SellBuy: Selling/Buying condition), trading actor (Actor: hospitals and schools/small businesses/multinational companies/low-income households/friends and family/neighbours), visibility of trading decision (Visibility: private/public), study context (Nation: Germany/UK), and the interaction between trading condition and trading actor.

\begin{tabular}{lrrrrrr}
\hline & Sum Sq & Mean Sq & NumDF & DenDF & F value & $\operatorname{Pr}(>\mathrm{F})$ \\
\hline SellBuy & 4.960399 & 4.960399 & 1 & 9691 & 1.552925 & 0.2127342 \\
& & & & & & \\
Actor & 2799.601305 & 559.920261 & 5 & 9691 & 175.291212 & 0.0000000 \\
Visibility & 5.149959 & 5.149959 & 1 & 881 & 1.612270 & 0.2045083 \\
Nation & 30.026857 & 30.026857 & 1 & 881 & 9.400346 & 0.0022356 \\
SellBuy:Actor & 5878.249054 & 1175.649811 & 5 & 9691 & 368.054336 & 0.0000000 \\
\hline
\end{tabular}

Supplementary Table 2: Difference between set selling and buying prices as a function of trading actor. Hochberg correction for multiple testing.

\begin{tabular}{lrrrr}
\hline & Value & Df & Chisq & $\operatorname{Pr}(>$ Chisq $)$ \\
\hline Hospitals / Schools & -0.6572077 & 1 & 59.564182 & 0.0000000 \\
Small businesses & 0.1872872 & 1 & 4.837221 & 0.0557035 \\
Multinational companies & 3.1611805 & 1 & 1378.092775 & 0.0000000 \\
Low-income households & -1.4392736 & 1 & 285.671269 & 0.0000000 \\
Friends /Family & -0.9035187 & 1 & 112.578172 & 0.0000000 \\
Neighbours & -0.0885358 & 1 & 1.080979 & 0.2984786 \\
\hline
\end{tabular}




\section{RQ2-3: Supplementary Tables}

Supplementary Table 3: Multilevel model results on the selling price settings as a function of trading actor (Actor: hospitals and schools/small businesses/multinational companies/lowincome households/friends and family/neighbours), visibility of trading decision (Visibility: private/public), study context (Nation: Germany/UK), and the interaction between the factors.

\begin{tabular}{|c|c|c|c|c|c|c|}
\hline & \multicolumn{3}{|r|}{ NumD } & \multicolumn{3}{|l|}{ DenD } \\
\hline & Sum Sq & Mean Sq & $\mathrm{F}$ & $\mathrm{F}$ & $F$ value & $\operatorname{Pr}(>\mathrm{F})$ \\
\hline \multirow[t]{2}{*}{ Actor } & 8263.50869 & 1652.701739 & 5 & 4405 & 630.811297 & 0.000000 \\
\hline & 7 & 4 & & & 6 & 0 \\
\hline \multirow[t]{2}{*}{ Visibility } & 3.281831 & 3.2818308 & 1 & 881 & 1.2526253 & 0.263356 \\
\hline & & & & & & \\
\hline Nation & 32.820500 & 32.8205001 & 1 & 881 & 12.5270893 & 0.000422 \\
\hline \multirow{2}{*}{ Actor:Visibility } & 3053206 & 06106597 & 5 & 4405 & 02330794 & 0948131 \\
\hline & & & & & ז & 0 \\
\hline \multirow[t]{2}{*}{ Actor:Nation } & 6.569668 & 1.3139337 & 5 & 4405 & 0.5015086 & 0.775337 \\
\hline & & & & & & 5 \\
\hline \multirow[t]{2}{*}{ Visibility:Nation } & 10.286836 & 10.2868357 & 1 & 881 & 3.9263299 & 0.047846 \\
\hline & & & & & & 1 \\
\hline \multirow{2}{*}{$\begin{array}{l}\text { Actor:Visibility:Natio } \\
\mathrm{n}\end{array}$} & 25.831437 & 5.1662874 & 5 & 4405 & 1.9718939 & 0.079544 \\
\hline & & & & & & 9 \\
\hline
\end{tabular}

Supplementary Table 4: Difference in set selling prices between set nations (Germany/UK) as a function of visibility of trading decision (Visibility: private/public). Hochberg correction for multiple testing.

\begin{tabular}{lrrrr}
\hline & Value & Df & Chisq & $\operatorname{Pr}(>$ Chisq) \\
\hline Private & -0.1444954 & 1 & 1.223151 & 0.2687431 \\
Public & -0.5120714 & 1 & 15.120323 & 0.0002017 \\
\hline
\end{tabular}

Supplementary Table 5: Multilevel model results on the buying price settings as a function of trading actor (Actor: hospitals and schools/small businesses/multinational companies/lowincome households/friends and family/neighbours), visibility of trading decision (Visibility: private/public), study context (Nation: Germany/UK), and the interaction between the factors.

\begin{tabular}{lrrrrrr}
\hline & Sum Sq & Mean Sq & NumDF & DenDF & F value & $\operatorname{Pr}(>\mathrm{F})$ \\
\hline Actor & 424.988686 & 84.997737 & 5 & 4405 & 27.9578516 & 0.0000000 \\
Visibility & 3.097333 & 3.097333 & 1 & 881 & 1.0187891 & 0.3130835 \\
Nation & 8.078407 & 8.078407 & 1 & 881 & 2.6571872 & 0.1034403 \\
Actor:Visibility & 5.192005 & 1.038401 & 5 & 4405 & 0.3415557 & 0.8878867 \\
Actor:Nation & 49.276558 & 9.855311 & 5 & 4405 & 3.2416550 & 0.0063378 \\
Visibility:Nation & 17.056857 & 17.056857 & 1 & 881 & 5.6104209 & 0.0180689 \\
Actor:Visibility:Nation & 5.355485 & 1.071097 & 5 & 4405 & 0.3523102 & 0.8810241 \\
\hline
\end{tabular}


Supplementary Table 6: Difference in set buying prices between set nations (Germany/UK) as a function of visibility of trading decision (Visibility: private/public). Hochberg correction for multiple testing.

\begin{tabular}{lrrrr}
\hline & Value & Df & Chisq & $\operatorname{Pr}(>$ Chisq $)$ \\
\hline Private & 0.0673798 & 1 & 0.274899 & 0.6000643 \\
Public & -0.3648160 & 1 & 7.932130 & 0.0097129 \\
\hline
\end{tabular}

Supplementary Table 7: Difference in set buying prices between set nations (Germany/UK) as a function of trading actor (Actor: hospitals and schools/small businesses/multinational companies/low-income households/friends and family/neighbours). Hochberg correction for multiple testing.

\begin{tabular}{lrrrr}
\hline & Value & Df & Chisq & $\operatorname{Pr}(>$ Chisq $)$ \\
\hline $\begin{array}{l}\text { Hospitals / Schools } \\
\text { Small businesses }\end{array}$ & -0.2625159 & 1 & 3.4751932 & 0.2866355 \\
$\begin{array}{l}\text { Multinational } \\
\text { companies }\end{array}$ & -0.1622600 & 1 & 1.3276717 & 0.3301421 \\
$\begin{array}{l}\text { Low-income } \\
\text { households }\end{array}$ & -0.2536572 & 1 & 3.2446070 & 0.2866355 \\
$\begin{array}{l}\text { Friends /Family } \\
\text { Neighbours }\end{array}$ & -0.3535121 & 1 & 6.3019704 & 0.0723623 \\
& -0.1371350 & 1 & 0.9483402 & 0.3301421 \\
\hline
\end{tabular}




\section{RQ4: Supplementary Tables}

Test of trait differences: Political orientation, climate change beliefs, and place attachment (SM Tables 8-21)

Selling condition

Supplementary Table 8: Multilevel model results on selling price settings as a function of trading actor (Actor: hospitals and schools/small businesses/multinational companies/lowincome households/friends and family/neighbours), visibility of trading decision (Visibility: private/public), study context (Nation: Germany/UK), individual differences and the interaction between trading actor and individual differences. Included individual differences were: political orientation (zPol_orientation), place attachment (zPlace), and climate change beliefs (zCC_beliefs). Individual difference variables were z-standardized before analysis.

\begin{tabular}{|c|c|c|c|c|c|c|}
\hline & & & NumD & DenD & & \\
\hline & Sum Sq & Mean Sq & $\mathrm{F}$ & $\mathrm{F}$ & F value & $\operatorname{Pr}(>\mathrm{F})$ \\
\hline Actor & 8187.00765 & 1637.40153 & 5 & 4350 & 642.820961 & 0.000000 \\
\hline zPol_orientation & 8.609682 & 8.609682 & 1 & 870 & 3.3800410 & 0.066331 \\
\hline zPlace & 23.803517 & 23.803517 & 1 & 870 & 9.3449283 & $\begin{array}{r}0.002304 \\
4\end{array}$ \\
\hline zCC_beliefs & 1.701411 & 1.701411 & 1 & 870 & 0.6679503 & $\begin{array}{r}0.413990 \\
9\end{array}$ \\
\hline Visibility & 4.878117 & 4.878117 & 1 & 870 & 1.9150806 & $\begin{array}{r}0.166754 \\
9\end{array}$ \\
\hline Nation & 26.817053 & 26.817053 & 1 & 870 & 10.5280001 & $\begin{array}{r}0.001220 \\
7\end{array}$ \\
\hline $\begin{array}{l}\text { Actor:ZPol_orientatio } \\
\mathrm{n}\end{array}$ & 163.290830 & 32.658166 & 5 & 4350 & 12.8211396 & $\begin{array}{r}0.000000 \\
0\end{array}$ \\
\hline Actor:zPlace & 37.157125 & 7.431425 & 5 & 4350 & 2.9174736 & $\begin{array}{r}0.012376 \\
9\end{array}$ \\
\hline Actor:zCC_beliefs & 36.988319 & 7.397664 & 5 & 4350 & 2.9042194 & $\begin{array}{r}0.012716 \\
7\end{array}$ \\
\hline
\end{tabular}

Supplementary Table 9: Linear model results on selling price settings for Hospitals/Schools as a function of visibility of trading decision (Visibility: private/public), study context (Nation: Germany/UK), political orientation (zPol_orientation), place attachment (zPlace), and climate change beliefs (zCC_beliefs). Individual difference variables were $z$-standardized before analysis.

\begin{tabular}{lrrrr}
\hline & Estimate & Std. Error & $\mathrm{t}$ value & $\operatorname{Pr}(>|\mathrm{t}|)$ \\
\hline (Intercept) & -1.0921417 & 0.1237183 & -8.827650 & 0.0000000 \\
ZPol_orientation & 0.1386483 & 0.0772401 & 1.795030 & 0.0729983 \\
zPlace & -0.1957004 & 0.0727792 & -2.688961 & 0.0073056 \\
zCC_beliefs & -0.1788415 & 0.0793240 & -2.254569 & 0.0244101 \\
Visibility & 0.2265350 & 0.1427406 & 1.587040 & 0.1128696 \\
Nation & 0.1685934 & 0.1434465 & 1.175305 & 0.2401966 \\
\hline
\end{tabular}


NON-PEER-REVIEWED PREPRINT | Posted 22 Dec 2021 
Supplementary Table 10: Linear model results on selling price settings for small businesses as a function of visibility of trading decision (Visibility: private/public), study context (Nation: Germany/UK), political orientation (zPol_orientation), place attachment (zPlace), and climate change beliefs (zCC_beliefs). Individual difference variables were $z$-standardized before analysis.

\begin{tabular}{lrrrr}
\hline & Estimate & Std. Error & $\mathrm{t}$ value & $\operatorname{Pr}(>|\mathrm{t}|)$ \\
\hline (Intercept) & -0.1827576 & 0.1060603 & -1.7231479 & 0.0852196 \\
zPol_orientation & 0.0455072 & 0.0662158 & 0.6872550 & 0.4921065 \\
zPlace & -0.1441302 & 0.0623916 & -2.3100895 & 0.0211180 \\
zCC_beliefs & -0.0582559 & 0.0680023 & -0.8566749 & 0.3918621 \\
Visibility & 0.0135071 & 0.1223677 & 0.1103816 & 0.9121324 \\
Nation & 0.2617455 & 0.1229728 & 2.1284828 & 0.0335795 \\
\hline
\end{tabular}

Supplementary Table 11: Linear model results on selling price settings for multinational companies as a function of visibility of trading decision (Visibility: private/public), study context (Nation: Germany/UK), political orientation (zPol_orientation), place attachment (zPlace), and climate change beliefs (zCC_beliefs). Individual difference variables were $z$ standardized before analysis.

\begin{tabular}{lrrrr}
\hline & Estimate & Std. Error & $\mathrm{t}$ value & $\operatorname{Pr}(>|\mathrm{t}|)$ \\
\hline (Intercept) & 1.9405791 & 0.1369650 & 14.1684255 & 0.0000000 \\
zPol_orientation & -0.2889704 & 0.0855104 & -3.3793618 & 0.0007591 \\
zPlace & -0.0051084 & 0.0805718 & -0.0634013 & 0.9494616 \\
zCC_beliefs & 0.0151160 & 0.0878174 & 0.1721298 & 0.8633758 \\
Visibility & 0.0802705 & 0.1580242 & 0.5079632 & 0.6116088 \\
Nation & 0.4652790 & 0.1588057 & 2.9298639 & 0.0034804 \\
\hline
\end{tabular}

Supplementary Table 12: Linear model results on selling price settings for low-income households as a function of visibility of trading decision (Visibility: private/public), study context (Nation: Germany/UK), political orientation (zPol_orientation), place attachment (zPlace), and climate change beliefs (zCC_beliefs). Individual difference variables were $z$ standardized before analysis.

\begin{tabular}{lrrrr}
\hline & Estimate & Std. Error & $\mathrm{t}$ value & $\operatorname{Pr}(>|\mathrm{t}|)$ \\
\hline (Intercept) & -1.7091930 & 0.1163717 & -14.687364 & 0.0000000 \\
zPol_orientation & 0.3440231 & 0.0726534 & 4.735124 & 0.0000026 \\
zPlace & -0.1402262 & 0.0684574 & -2.048371 & 0.0408254 \\
zCC_beliefs & -0.1513384 & 0.0746136 & -2.028294 & 0.0428365 \\
Visibility & 0.2206952 & 0.1342644 & 1.643735 & 0.1005947 \\
Nation & 0.1778343 & 0.1349284 & 1.317990 & 0.1878564 \\
\hline
\end{tabular}

Supplementary Table 13: Linear model results on selling price settings for friends/family as a function of visibility of trading decision (Visibility: private/public), study context (Nation: Germany/UK), political orientation (zPol_orientation), place attachment (zPlace), and 
climate change beliefs (zCC_beliefs). Individual difference variables were z-standardized before analysis.

\begin{tabular}{lrrrr}
\hline & Estimate & Std. Error & $\mathrm{t}$ value & $\operatorname{Pr}(>|\mathrm{t}|)$ \\
\hline (Intercept) & -1.6489594 & 0.1186196 & -13.9012351 & 0.0000000 \\
zPol_orientation & 0.1995205 & 0.0740569 & 2.6941519 & 0.0071937 \\
zPlace & -0.0954350 & 0.0697798 & -1.3676584 & 0.1717747 \\
zCC_beliefs & 0.0193745 & 0.0760549 & 0.2547438 & 0.7989816 \\
Visibility & 0.1241562 & 0.1368580 & 0.9071900 & 0.3645593 \\
Nation & 0.3874755 & 0.1375349 & 2.8172896 & 0.0049536 \\
\hline
\end{tabular}

Supplementary Table 14: Linear model results on selling price settings for neighbours as a function of visibility of trading decision (Visibility: private/public), study context (Nation: Germany/UK), political orientation (zPol_orientation), place attachment (zPlace), and climate change beliefs (zCC_beliefs). Individual difference variables were $z$-standardized before analysis.

\begin{tabular}{lrrrr}
\hline & Estimate & Std. Error & $\mathrm{t}$ value & $\operatorname{Pr}(>|\mathrm{t}|)$ \\
\hline (Intercept) & -0.7161915 & 0.1032762 & -6.9347209 & 0.0000000 \\
zPol_orientation & 0.1159620 & 0.0644776 & 1.7984842 & 0.0724492 \\
zPlace & -0.2884449 & 0.0607538 & -4.7477657 & 0.0000024 \\
zCC_beliefs & 0.1007100 & 0.0662172 & 1.5209035 & 0.1286499 \\
Visibility & 0.1064288 & 0.1191555 & 0.8931925 & 0.3720028 \\
Nation & 0.3571400 & 0.1197447 & 2.9825115 & 0.0029393 \\
\hline
\end{tabular}


$\underline{\text { Buying condition }}$

Supplementary Table 15: Multilevel model results on buying price settings as a function of trading actor (Actor: hospitals and schools/small businesses/multinational companies/lowincome households/friends and family/neighbours), visibility of trading decision (Visibility: private/public), study context (Nation: Germany/UK), individual differences and the interaction between trading actor and individual differences. Included individual differences were: political orientation (zPol_orientation), place attachment (zPlace), and climate change beliefs (zCC_beliefs). Individual difference variables were z-standardized before analysis.

\begin{tabular}{lrrrrrr}
\hline & Sum Sq & Mean Sq & NumDF & DenDF & F value & $\operatorname{Pr}(>\mathrm{F})$ \\
\hline Actor_f & 437.4947370 & 87.4989474 & 5 & 4350.0000 & 29.3642635 & 0.0000000 \\
zPol_orientation & 7.3736368 & 7.3736368 & 1 & 869.9999 & 2.4745602 & 0.1160654 \\
zPlace & 3.0657386 & 3.0657386 & 1 & 869.9999 & 1.0288484 & 0.3107113 \\
zCC_beliefs & 0.2336134 & 0.2336134 & 1 & 869.9999 & 0.0783996 & 0.7795445 \\
Visibility_f & 2.1503042 & 2.1503042 & 1 & 869.9999 & 0.7216327 & 0.3958426 \\
Nation_f & 10.0137241 & 10.0137241 & 1 & 869.9999 & 3.3605620 & 0.0671168 \\
Actor_f:ZPol_orientation & 42.5302576 & 8.5060515 & 5 & 4350.0000 & 2.8545936 & 0.0140710 \\
Actor_f:zPlace & 18.4582210 & 3.6916442 & 5 & 4350.0000 & 1.2388996 & 0.2879614 \\
Actor_f:zCC_beliefs & 70.3343675 & 14.0668735 & 5 & 4350.0000 & 4.7207811 & 0.0002651 \\
\hline
\end{tabular}

Supplementary Table 16: Linear model results on buying price settings for Hospitals/Schools as a function of visibility of trading decision (Visibility: private/public), study context (Nation: Germany/UK), political orientation (zPol_orientation), place attachment (zPlace), and climate change beliefs (zCC_beliefs). Individual difference variables were $z$-standardized before analysis.

\begin{tabular}{lrrrr}
\hline & Estimate & Std. Error & $\mathrm{t}$ value & $\operatorname{Pr}(>|\mathrm{t}|)$ \\
\hline (Intercept) & -0.4272075 & 0.1167111 & -3.6603837 & 0.0002671 \\
zPol_orientation & -0.1534479 & 0.0728654 & -2.1059099 & 0.0355002 \\
zPlace & 0.0556097 & 0.0686571 & 0.8099630 & 0.4181844 \\
zCC_beliefs & 0.1175864 & 0.0748313 & 1.5713541 & 0.1164665 \\
Visibility & 0.0505416 & 0.1346561 & 0.3753386 & 0.7075008 \\
Nation & 0.3384319 & 0.1353220 & 2.5009377 & 0.0125706 \\
\hline
\end{tabular}


Supplementary Table 17: Linear model results on buying price settings for small businesses as a function of visibility of trading decision (Visibility: private/public), study context (Nation: Germany/UK), political orientation (zPol_orientation), place attachment (zPlace), and climate change beliefs (zCC_beliefs). Individual difference variables were $z$-standardized before analysis.

\begin{tabular}{lrrrr}
\hline & Estimate & Std. Error & $\mathrm{t}$ value & $\operatorname{Pr}(>|\mathrm{t}|)$ \\
\hline (Intercept) & -0.3379823 & 0.1000096 & -3.3794992 & 0.0007587 \\
zPol_orientation & -0.1194142 & 0.0624382 & -1.9125177 & 0.0561402 \\
zPlace & 0.0592617 & 0.0588322 & 1.0073008 & 0.3140723 \\
zCC_beliefs & -0.0108253 & 0.0641228 & -0.1688218 & 0.8659763 \\
Visibility & 0.0251345 & 0.1153866 & 0.2178289 & 0.8276139 \\
Nation & 0.1919346 & 0.1159572 & 1.6552186 & 0.0982433 \\
\hline
\end{tabular}

Supplementary Table 18: Linear model results on buying price settings for multinational companies as a function of visibility of trading decision (Visibility: private/public), study context (Nation: Germany/UK), political orientation (zPol_orientation), place attachment (zPlace), and climate change beliefs (zCC_beliefs). Individual difference variables were $z$ standardized before analysis.

\begin{tabular}{lrrrr}
\hline & Estimate & Std. Error & $\mathrm{t}$ value & $\operatorname{Pr}(>|\mathrm{t}|)$ \\
\hline (Intercept) & -0.8351982 & 0.1726010 & -4.8388963 & 0.0000015 \\
zPol_orientation & 0.1177859 & 0.1077587 & 1.0930531 & 0.2746752 \\
zPlace & -0.0648414 & 0.1015352 & -0.6386104 & 0.5232457 \\
zCC_beliefs & -0.2752751 & 0.1106659 & -2.4874421 & 0.0130542 \\
Visibility & 0.0609654 & 0.1991393 & 0.3061443 & 0.7595685 \\
Nation & -0.3300108 & 0.2001241 & -1.6490305 & 0.0995049 \\
\hline
\end{tabular}

Supplementary Table 19: Linear model results on buying price settings for low-income households as a function of visibility of trading decision (Visibility: private/public), study context (Nation: Germany/UK), political orientation (zPol_orientation), place attachment (zPlace), and climate change beliefs (zCC_beliefs). Individual difference variables were $z$ standardized before analysis.

\begin{tabular}{lrrrr}
\hline & Estimate & Std. Error & $\mathrm{t}$ value & $\operatorname{Pr}(>|\mathrm{t}|)$ \\
\hline (Intercept) & -0.2470715 & 0.1210890 & -2.0404119 & 0.0416129 \\
zPol_orientation & -0.2032155 & 0.0755986 & -2.6880857 & 0.0073246 \\
zPlace & 0.1098933 & 0.0712325 & 1.5427412 & 0.1232598 \\
zCC_beliefs & 0.1476995 & 0.0776382 & 1.9024067 & 0.0574503 \\
Visibility & 0.0505358 & 0.1397071 & 0.3617265 & 0.7176448 \\
Nation & 0.3174070 & 0.1403981 & 2.2607646 & 0.0240219 \\
\hline
\end{tabular}

Supplementary Table 20: Linear model results on buying price settings for friends/family as a function of visibility of trading decision (Visibility: private/public), study context (Nation: Germany/UK), political orientation (zPol_orientation), place attachment (zPlace), and 
climate change beliefs (zCC_beliefs). Individual difference variables were z-standardized before analysis.

\begin{tabular}{lrrrr}
\hline & Estimate & Std. Error & $\mathrm{t}$ value & $\operatorname{Pr}(>|\mathrm{t}|)$ \\
\hline (Intercept) & -0.7633230 & 0.1137774 & -6.7089148 & 0.0000000 \\
zPol_orientation & -0.0671642 & 0.0710338 & -0.9455250 & 0.3446552 \\
zPlace & 0.1183220 & 0.0669313 & 1.7678123 & 0.0774452 \\
zCC_beliefs & 0.0629269 & 0.0729503 & 0.8626002 & 0.3885967 \\
Visibility & 0.1616861 & 0.1312713 & 1.2316942 & 0.2183984 \\
Nation & 0.3667838 & 0.1319205 & 2.7803396 & 0.0055483 \\
\hline
\end{tabular}

Supplementary Table 21: Linear model results on buying price settings for neighbours as a function of visibility of trading decision (Visibility: private/public), study context (Nation: Germany/UK), political orientation (zPol_orientation), place attachment (zPlace), and climate change beliefs (zCC_beliefs). Individual difference variables were $z$-standardized before analysis.

\begin{tabular}{lrrrr}
\hline & Estimate & Std. Error & $\mathrm{t}$ value & $\operatorname{Pr}(>|\mathrm{t}|)$ \\
\hline (Intercept) & -0.5279520 & 0.0950188 & -5.5562923 & 0.0000000 \\
zPol_orientation & -0.0437640 & 0.0593223 & -0.7377327 & 0.4608772 \\
zPlace & 0.0068352 & 0.0558963 & 0.1222831 & 0.9027032 \\
zCC_beliefs & 0.0436599 & 0.0609228 & 0.7166429 & 0.4737881 \\
Visibility & 0.1194001 & 0.1096284 & 1.0891346 & 0.2763982 \\
Nation & 0.1309552 & 0.1101706 & 1.1886588 & 0.2349006 \\
\hline
\end{tabular}


Test of differences in trust in trading actors (SM Table 22)

Supplementary Table 22: Post-hoc tests on differences in reported trust in the trading actors (Tukey corrected)

\begin{tabular}{lrrrrr}
\hline contrast & estimate & SE & df & t.ratio & p.value \\
\hline $1-2$ & 0.2531215 & 0.0367625 & 4410.006 & 6.885316 & 0.0000000 \\
$1-3$ & 1.2769580 & 0.0367625 & 4410.006 & 34.735340 & 0.0000000 \\
$1-4$ & 0.6288309 & 0.0367625 & 4410.006 & 17.105225 & 0.0000000 \\
$1-5$ & -0.6526674 & 0.0367625 & 4410.006 & - & 0.0000000 \\
& & & & 17.753618 & \\
$1-6$ & 0.2292849 & 0.0367625 & 4410.006 & 6.236923 & 0.0000001 \\
$2-3$ & 1.0238365 & 0.0367625 & 4410.006 & 27.850024 & 0.0000000 \\
$2-4$ & 0.3757094 & 0.0367625 & 4410.006 & 10.219909 & 0.0000000 \\
$2-5$ & -0.9057889 & 0.0367625 & 4410.006 & - & 0.0000000 \\
& & & & 24.638935 & \\
$2-6$ & -0.0238365 & 0.0367625 & 4410.006 & -0.648393 & 0.9872444 \\
$3-4$ & -0.6481271 & 0.0367625 & 4410.006 & - & 0.0000000 \\
& & & & 17.630115 & \\
$3-5$ & -1.9296254 & 0.0367625 & 4410.006 & - & 0.0000000 \\
& & & & 52.488958 & \\
$3-6$ & -1.0476731 & 0.0367625 & 4410.006 & - & 0.0000000 \\
& & & & 28.498417 & \\
$4-5$ & -1.2814983 & 0.0367625 & 4410.006 & - & 0.0000000 \\
$4-6$ & -0.3995460 & 0.0367625 & 4410.006 & - & 0.0000000 \\
& & & & 10.868302 & \\
$5-6$ & 0.8819523 & 0.0367625 & 4410.006 & 23.990541 & 0.0000000 \\
\hline
\end{tabular}

Note. actor coding: $1=$ Hospitals/Schools $2=$ Small businesses $3=$

Multinational companies $4=$ Low-income households $5=$

Friends/Family $6=$ Neighbours 
MLM analysis on trust effects as a function of actor (SM Tables 23-34)

Selling condition

Supplementary Table 23: Linear model results on selling price settings for Hospitals/Schools as a function of reported trust in the respective trading actor (ztrust), visibility of trading decision (Visibility: private/public), study context (Nation: Germany/UK), political orientation (zPol_orientation), place attachment (zPlace), and climate change beliefs $\left(z C C \_\right.$beliefs $)$. Individual difference variables were z-standardized before analysis.

\begin{tabular}{lrrrr}
\hline & Estimate & Std. Error & $\mathrm{t}$ value & $\operatorname{Pr}(>|\mathrm{t}|)$ \\
\hline (Intercept) & -1.0556936 & 0.1229864 & -8.583821 & 0.0000000 \\
ztrust & -0.3513130 & 0.0875369 & -4.013315 & 0.0000651 \\
zPol_orientation & 0.1222458 & 0.0766826 & 1.594181 & 0.1112617 \\
zPlace & -0.1018332 & 0.0758474 & -1.342607 & 0.1797525 \\
zCC_beliefs & -0.1389805 & 0.0792642 & -1.753383 & 0.0798914 \\
Visibility & 0.2253417 & 0.1415092 & 1.592417 & 0.1116572 \\
Nation & 0.2802607 & 0.1449051 & 1.934098 & 0.0534278 \\
\hline
\end{tabular}

Supplementary Table 24: Linear model results on selling price settings for small businesses as a function of reported trust in the respective trading actor (ztrust), visibility of trading decision (Visibility: private/public), study context (Nation: Germany/UK), political orientation (zPol_orientation), place attachment (zPlace), and climate change beliefs $\left(z C C \_\right.$beliefs). Individual difference variables were $z$-standardized before analysis.

\begin{tabular}{lrrrr}
\hline & Estimate & Std. Error & $\mathrm{t}$ value & $\operatorname{Pr}(>|\mathrm{t}|)$ \\
\hline (Intercept) & - & 0.1055109 & - & 0.0559570 \\
& 0.2019427 & & 1.9139503 & \\
ztrust & - & 0.0863384 & - & 0.0004610 \\
& 0.3035638 & & 3.5159775 & \\
zPol_orientation & 0.0532355 & 0.0658214 & 0.8087869 & 0.4188606 \\
zPlace & - & 0.0667030 & - & 0.3889227 \\
& 0.0574985 & & 0.8620077 & \\
zCC_beliefs & - & 0.0676678 & - & 0.5081077 \\
& 0.0448004 & & 0.6620628 & \\
Visibility & 0.0248418 & 0.1216136 & 0.2042682 & 0.8381920 \\
Nation & 0.3119944 & 0.1230052 & 2.5364327 & 0.0113741 \\
\hline
\end{tabular}


Supplementary Table 25: Linear model results on selling price settings for multinational companies as a function of reported trust in the respective trading actor (ztrust), visibility of trading decision (Visibility: private/public), study context (Nation: Germany/UK), political orientation (zPol_orientation), place attachment (zPlace), and climate change beliefs (zCC_beliefs). Individual difference variables were z-standardized before analysis.

\begin{tabular}{lrrrr}
\hline & Estimate & Std. Error & t value & $\operatorname{Pr}(>|t|)$ \\
\hline (Intercept) & 1.5887108 & 0.1577430 & 10.0715142 & 0.0000000 \\
ztrust & -0.374440 & 0.0858397 & -4.3620900 & 0.0000144 \\
zPol_orientation & -0.227528 & 0.0857961 & -2.6519707 & 0.0081492 \\
zPlace & 0.0588665 & 0.0810816 & 0.7260150 & 0.4680264 \\
zCC_beliefs & 0.0075665 & 0.0869325 & 0.0870384 & 0.9306612 \\
Visibility & 0.0557319 & 0.1565020 & 0.3561098 & 0.7218454 \\
Nation & 0.5354485 & 0.1579954 & 3.3890132 & 0.0007332 \\
\hline
\end{tabular}

Supplementary Table 26: Linear model results on selling price settings for low-income households as a function of reported trust in the respective trading actor (ztrust), visibility of trading decision (Visibility: private/public), study context (Nation: Germany/UK), political orientation (zPol_orientation), place attachment (zPlace), and climate change beliefs $\left(z C C \_b e l i e f s\right)$. Individual difference variables were z-standardized before analysis.

\begin{tabular}{lrrrr}
\hline & Estimate & Std. Error & $\mathrm{t}$ value & $\operatorname{Pr}(>|\mathrm{t}|)$ \\
\hline (Intercept) & - & 0.1189183 & - & 0.0000000 \\
& 1.7790397 & & 14.9601785 & \\
ztrust & - & 0.0848913 & -2.6528943 & 0.0081271 \\
& 0.2252077 & & & \\
zPol_orientation & 0.3311011 & 0.0725646 & 4.5628488 & 0.0000058 \\
zPlace & - & 0.0735323 & -0.9169291 & 0.3594360 \\
& 0.0674239 & & & \\
zCC_beliefs & - & 0.0745976 & -1.8146027 & 0.0699321 \\
& 0.1353651 & & & \\
Visibility & 0.2317784 & 0.1338630 & 1.7314600 & 0.0837271 \\
Nation & 0.1708420 & 0.1344853 & 1.2703400 & 0.2043059 \\
\hline
\end{tabular}

Supplementary Table 27: Linear model results on selling price settings for friends/family as a function of reported trust in the respective trading actor (ztrust), visibility of trading decision (Visibility: private/public), study context (Nation: Germany/UK), political orientation (zPol_orientation), place attachment (zPlace), and climate change beliefs $\left(z C C \_b e l i e f s\right)$. Individual difference variables were z-standardized before analysis.

\begin{tabular}{lrrrr}
\hline & Estimate & Std. Error & $\mathrm{t}$ value & $\operatorname{Pr}(>|\mathrm{t}|)$ \\
\hline Intercept) & - & 0.1348809 & - & 0.0000000 \\
& 1.1556991 & & 8.5682917 & \\
ztrust & - & 0.0929393 & - & 0.0000000 \\
& 0.6565180 & & 7.0639404 & \\
zPol_orientation & 0.1854882 & 0.0720736 & 2.5735955 & 0.0102307 \\
zPlace & 0.0455812 & 0.0707596 & 0.6441705 & 0.5196361
\end{tabular}




\begin{tabular}{lllll} 
zCC_beliefs & 0.0910675 & 0.0746828 & 1.2193906 & 0.2230292 \\
Visibility & 0.1489222 & 0.1331884 & 1.1181324 & 0.2638216 \\
Nation & 0.4765819 & 0.1343940 & 3.5461558 & 0.0004119 \\
\hline
\end{tabular}

Supplementary Table 28: Linear model results on selling price settings for neighbours as a function of reported trust in the respective trading actor (ztrust), visibility of trading decision (Visibility: private/public), study context (Nation: Germany/UK), political orientation (zPol_orientation), place attachment (zPlace), and climate change beliefs (zCC_beliefs). Individual difference variables were z-standardized before analysis.

\begin{tabular}{lrrrr}
\hline & Estimate & Std. Error & $\mathrm{t}$ value & $\operatorname{Pr}(>|\mathrm{t}|)$ \\
\hline (Intercept) & - & 0.1027737 & - & 0.0000000 \\
& 0.7052677 & & 6.8623366 & \\
ztrust & - & 0.0814836 & - & 0.0012961 \\
& 0.2629832 & & 3.2274393 & \\
zPol_orientation & 0.1255156 & 0.0641974 & 1.9551510 & 0.0508877 \\
zPlace & - & 0.0718506 & - & 0.0235583 \\
& 0.1629775 & & 2.2682829 & \\
zCC_beliefs & 0.0950012 & 0.0658831 & 1.4419673 & 0.1496744 \\
Visibility & 0.1055178 & 0.1185117 & 0.8903574 & 0.3735221 \\
Nation & 0.3641423 & 0.1191172 & 3.0570073 & 0.0023045 \\
\hline
\end{tabular}


$\underline{\text { Buying condition }}$

Supplementary Table 29: Linear model results on buying price settings for Hospitals/Schools as a function of reported trust in the respective trading actor (ztrust), visibility of trading decision (Visibility: private/public), study context (Nation: Germany/UK), political orientation (zPol_orientation), place attachment (zPlace), and climate change beliefs (zCC_beliefs). Individual difference variables were $z$-standardized before analysis.

\begin{tabular}{lrrrr}
\hline & Estimate & Std. Error & $\mathrm{t}$ value & $\operatorname{Pr}(>|\mathrm{t}|)$ \\
\hline (Intercept) & - & 0.1167747 & - & 0.0001430 \\
& 0.4460840 & & 3.8200412 & \\
ztrust & 0.1819459 & 0.0831156 & 2.1890710 & 0.0288589 \\
zPol_orientation & - & 0.0728095 & - & 0.0468119 \\
& 0.1449530 & & 1.9908538 & \\
zPlace & 0.0069957 & 0.0720165 & 0.0971403 & 0.9226376 \\
zCC_beliefs & 0.0969423 & 0.0752608 & 1.2880858 & 0.1980613 \\
Visibility & 0.0511597 & 0.1343619 & 0.3807605 & 0.7034747 \\
Nation & 0.2805992 & 0.1375863 & 2.0394415 & 0.0417101 \\
\hline
\end{tabular}

Supplementary Table 30: Linear model results on buying price settings for small businesses as a function of reported trust in the respective trading actor (ztrust), visibility of trading decision (Visibility: private/public), study context (Nation: Germany/UK), political orientation (zPol_orientation), place attachment (zPlace), and climate change beliefs (zCC_beliefs). Individual difference variables were z-standardized before analysis.

\begin{tabular}{lrrrr}
\hline & Estimate & Std. Error & $\mathrm{t}$ value & $\operatorname{Pr}(>|\mathrm{t}|)$ \\
\hline (Intercept) & -0.3316258 & 0.1001142 & -3.3124751 & 0.0009632 \\
ztrust & 0.1005785 & 0.0819223 & 1.2277299 & 0.2198832 \\
zPol_orientation & -0.1219748 & 0.0624547 & -1.9530113 & 0.0511411 \\
zPlace & 0.0305584 & 0.0632912 & 0.4828219 & 0.6293446 \\
zCC_beliefs & -0.0152835 & 0.0642067 & -0.2380355 & 0.8119101 \\
Visibility & 0.0213791 & 0.1153933 & 0.1852714 & 0.8530597 \\
Nation & 0.1752859 & 0.1167137 & 1.5018451 & 0.1335029 \\
\hline
\end{tabular}

Supplementary Table 31: Linear model results on buying price settings for multinational companies as a function of reported trust in the respective trading actor (ztrust), visibility of trading decision (Visibility: private/public), study context (Nation: Germany/UK), political orientation (zPol_orientation), place attachment (zPlace), and climate change beliefs (zCC_beliefs). Individual difference variables were z-standardized before analysis.

\begin{tabular}{lrrrr}
\hline & Estimate & Std. Error & $\mathrm{t}$ value & $\operatorname{Pr}(>|\mathrm{t}|)$ \\
\hline (Intercept) & -0.4074545 & 0.1989371 & -2.0481575 & 0.0408467 \\
ztrust & 0.4551832 & 0.1082565 & 4.2046744 & 0.0000289 \\
zPol_orientation & 0.0430952 & 0.1082015 & 0.3982864 & 0.6905176 \\
zPlace & -0.1426115 & 0.1022558 & -1.3946542 & 0.1634790 \\
zCC_beliefs & -0.2660977 & 0.1096347 & -2.4271297 & 0.0154225 \\
Visibility & 0.0907953 & 0.1973721 & 0.4600211 & 0.6456170
\end{tabular}


Supplementary Table 32: Linear model results on buying price settings for low-income households as a function of reported trust in the respective trading actor (ztrust), visibility of trading decision (Visibility: private/public), study context (Nation: Germany/UK), political orientation (zPol_orientation), place attachment (zPlace), and climate change beliefs (zCC_beliefs). Individual difference variables were z-standardized before analysis.

\begin{tabular}{lrrrr}
\hline & Estimate & Std. Error & $\mathrm{t}$ value & $\operatorname{Pr}(>|\mathrm{t}|)$ \\
\hline (Intercept) & -0.2311137 & 0.1242183 & -1.8605455 & 0.0631483 \\
ztrust & 0.0514529 & 0.0886747 & 0.5802431 & 0.5619022 \\
zPol_orientation & -0.2002633 & 0.0757986 & -2.6420445 & 0.0083899 \\
zPlace & 0.0932603 & 0.0768094 & 1.2141773 & 0.2250122 \\
zCC_beliefs & 0.1440501 & 0.0779223 & 1.8486380 & 0.0648520 \\
Visibility & 0.0480036 & 0.1398289 & 0.3433025 & 0.7314545 \\
Nation & 0.3190045 & 0.1404790 & 2.2708345 & 0.0234026 \\
\hline
\end{tabular}

Supplementary Table 33: Linear model results on buying price settings for friends/family as a function of reported trust in the respective trading actor (ztrust), visibility of trading decision (Visibility: private/public), study context (Nation: Germany/UK), political orientation (zPol_orientation), place attachment (zPlace), and climate change beliefs (zCC_beliefs). Individual difference variables were $z$-standardized before analysis.

\begin{tabular}{lrrrr}
\hline & Estimate & Std. Error & $\mathrm{t}$ value & $\operatorname{Pr}(>|\mathrm{t}|)$ \\
\hline (Intercept) & -0.7051777 & 0.1330077 & -5.3017816 & 0.0000001 \\
ztrust & -0.0773901 & 0.0916486 & -0.8444217 & 0.3986678 \\
zPol_orientation & -0.0688184 & 0.0710726 & -0.9682826 & 0.3331745 \\
zPlace & 0.1349450 & 0.0697769 & 1.9339494 & 0.0534460 \\
zCC_beliefs & 0.0713781 & 0.0736456 & 0.9692101 & 0.3327119 \\
Visibility & 0.1646055 & 0.1313386 & 1.2532910 & 0.2104393 \\
Nation & 0.3772876 & 0.1325275 & 2.8468635 & 0.0045200 \\
\hline
\end{tabular}


Supplementary Table 34: Linear model results on buying price settings for neighbours as a function of reported trust in the respective trading actor (ztrust), visibility of trading decision (Visibility: private/public), study context (Nation: Germany/UK), political orientation (zPol_orientation), place attachment (zPlace), and climate change beliefs (zCC_beliefs). Individual difference variables were z-standardized before analysis.

\begin{tabular}{lrrrr}
\hline & Estimate & Std. Error & $\mathrm{t}$ value & $\operatorname{Pr}(>|\mathrm{t}|)$ \\
\hline (Intercept) & -0.5320733 & 0.0950300 & -5.5990052 & 0.0000000 \\
ztrust & 0.0992175 & 0.0753440 & 1.3168608 & 0.1882349 \\
zPol_orientation & -0.0473684 & 0.0593603 & -0.7979810 & 0.4251010 \\
zPlace & -0.0405008 & 0.0664369 & -0.6096128 & 0.5422788 \\
zCC_beliefs & 0.0458137 & 0.0609189 & 0.7520440 & 0.4522297 \\
Visibility & 0.1197438 & 0.1095822 & 1.0927304 & 0.2748171 \\
Nation & 0.1283134 & 0.1101421 & 1.1649810 & 0.2443486 \\
\hline
\end{tabular}




\section{Data Availability Statement: Supplementary Tables}

Supplementary Table 35: TREQ checklist for reporting of tools that promote transparency, reproducibility, and quality of research [1].

\begin{tabular}{|c|c|c|}
\hline Tools & Check & Comments \\
\hline \multicolumn{3}{|l|}{ Pre-registration } \\
\hline This study has pre-analysis plan. & Yes & Explanation if no: \\
\hline \multicolumn{3}{|l|}{ If yes } \\
\hline URL & & $\begin{array}{l}\text { https://aspredicted.org/jr3jv.pd } \\
f\end{array}$ \\
\hline $\begin{array}{l}\text { Was it registered before data } \\
\text { collection? }\end{array}$ & Yes & Explanation if no: \\
\hline $\begin{array}{l}\text { Does the paper mention and } \\
\text { explain deviations from the } \\
\text { PAP? }\end{array}$ & $\begin{array}{l}\text { Not applicable (no } \\
\text { deviations) }\end{array}$ & $\begin{array}{l}\text { If yes, specify section of paper, } \\
\text { or explanation if no: }\end{array}$ \\
\hline \multicolumn{3}{|l|}{ Reporting guidelines } \\
\hline $\begin{array}{l}\text { This paper follows a reporting } \\
\text { guideline. }\end{array}$ & Yes & \\
\hline \multicolumn{3}{|l|}{ If yes } \\
\hline Which one? & & CONSORT [2] \\
\hline \multicolumn{3}{|l|}{ Open Data and Code } \\
\hline Data/code are publicly available & Yes, data and code & \\
\hline $\begin{array}{l}\text { Does the paper make a statement } \\
\text { on data and code availability? }\end{array}$ & Yes, on data and code & $\begin{array}{l}\text { See Data Availability } \\
\text { Statement in main manuscript }\end{array}$ \\
\hline \multicolumn{3}{|l|}{ If yes } \\
\hline What is / are the link(s)? & $O S F$ & $\begin{array}{l}\text { [to be shared upon journal } \\
\text { publication] }\end{array}$ \\
\hline $\begin{array}{l}\text { Have steps been taken to ensure } \\
\text { the data are FAIR? }\end{array}$ & $\begin{array}{l}\text { Yes } \\
\text { No }\end{array}$ & \\
\hline Has meta-data been uploaded? & $\begin{array}{l}\text { Yes } \\
\text { No }\end{array}$ & \\
\hline \multicolumn{3}{|l|}{ Preprints } \\
\hline Have you uploaded a preprint? & $\begin{array}{l}\text { Planned following } \\
\text { submission }\end{array}$ & \\
\hline \multicolumn{3}{|l|}{ If yes } \\
\hline \multicolumn{3}{|l|}{ What is the link? } \\
\hline \multicolumn{3}{|l|}{ If planned } \\
\hline Which preprint server/location? & & OSF/PsyArXiv \\
\hline
\end{tabular}




\section{References}

[1] Huebner GM, Fell MJ, Watson NE. Improving energy research practices: guidance for transparency, reproducibility and quality. Build Cities 2021;2:1-20.

https://doi.org/10.5334/bc.67.

[2] Schulz KF, Altman DG, Moher D. CONSORT 2010 Statement: updated guidelines for reporting parallel group randomised trials. BMJ 2010;340:c332-c332.

https://doi.org/10.1136/bmj.c332. 